ANL-6606

Technology -

Feed Materials

(TID-4500, 19th Ed.)

AEC Research and

Development Report

ARGONNE NATIONAL LABORATORY

9700 South Cass Avenue

Argonne, Illinois

A FLUID-BED PROCESS FOR THE DIRECT CONVERSION OF

URANIUM HEXAFLUORIDE TO URANIUM DIOXIDE

by

I. E. Knudsen, H. E. Hootman, and N. M. Levitz

Chemical Engineering Division

February 1963

Operated by The University of Chicago

under

Contract W-31-109-eng-38

with the

U. S. Atomic Energy Commission 


\section{DISCLAIMER}

This report was prepared as an account of work sponsored by an agency of the United States Government. Neither the United States Government nor any agency Thereof, nor any of their employees, makes any warranty, express or implied, or assumes any legal liability or responsibility for the accuracy, completeness, or usefulness of any information, apparatus, product, or process disclosed, or represents that its use would not infringe privately owned rights. Reference herein to any specific commercial product, process, or service by trade name, trademark, manufacturer, or otherwise does not necessarily constitute or imply its endorsement, recommendation, or favoring by the United States Government or any agency thereof. The views and opinions of authors expressed herein do not necessarily state or reflect those of the United States Government or any agency thereof. 


\section{DISCLAIMER}

Portions of this document may be illegible in electronic image products. Images are produced from the best available original document. 
TABLE OF CONTENTS

Page

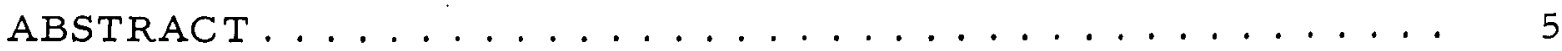

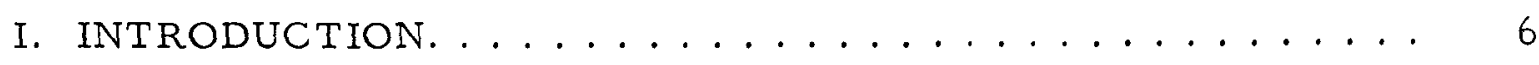

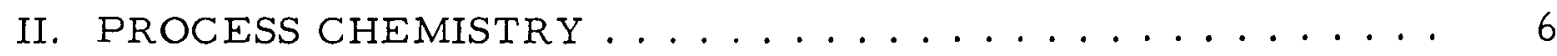

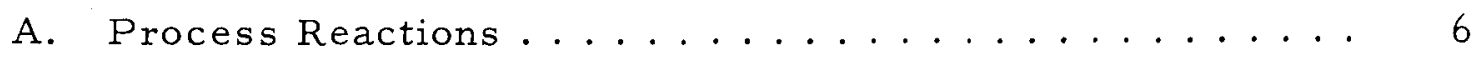

B. Literature Review ................... 7

1. Uranium Hexafluoride Reactions............. 7

2. Intermediate-compound Reactions ........... 8

III. APPARATUS AND PROCEDURE. . . . . . . . . . . . . 9

IV. PROCESS DEVELOPMENT STUDIES . . . . . . . . . . . 12

A. Results and Discussion of the Fluid-bed Hydrolysis of

Uranium Hexafluoride to Uranyl Fluoride. . . . . . . . . . 12

1. Preliminary Hydrolysis Work. ............. 12

2. Hydrolysis Studies with Particle Recycle . . . . . . . 14

3. Demonstration Runs on the Hydrolysis Step. ...... 16

4. Additional Hydrolysis Studies.............. 19

a. High-temperature Hydrolysis . . . . . . . . . 19

b. Particle Size Effects during Hydrolysis . . . . . . . . 21

B. Fluid-bed Reduction of Uranyl Fluoride to Uranium

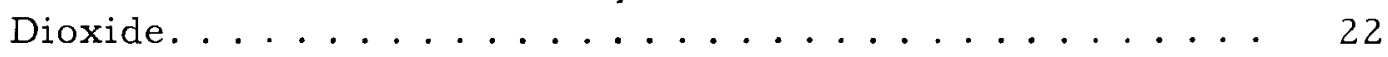

1. Results and Discussion of Batch Fluid-bed Reduction

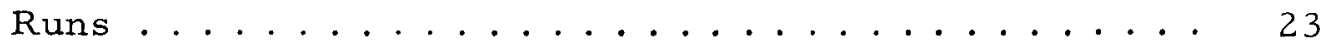

a. Effect of Gas Composition ............. 23

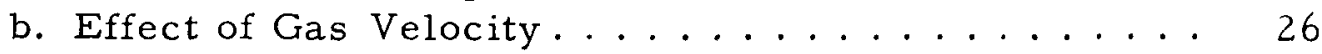

c. Effect of Temperature............... 27

d. Effect of Bed Depth................ 27

e. Effect of Initial Particle Size ........... 28

2. Powder Properties..................... 29

C. Results of Sintering Tests on Dioxide Produced by the

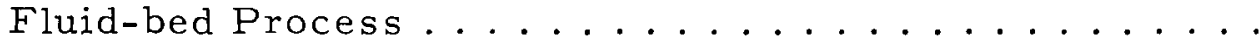


2

TABLE OF CONTENTS

$\underline{\text { Page }}$

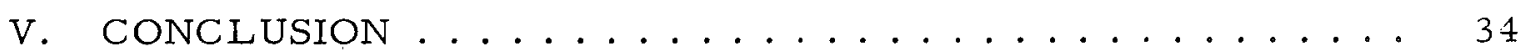

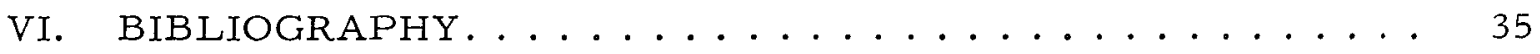

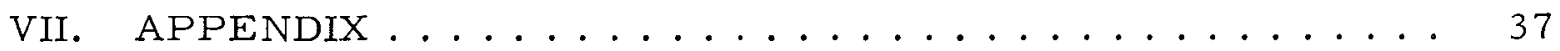

A. Fluid-bed Studies on the Preparation of Dense Uranium Dioxide Particles in a Single-step Operation. . . . . . . 37

B. A Bench-scale Study of the Vapor-phase Reaction of Steam and Uranium Hexafluoride ............ 41

C. Method Used for Calculating Particle Growth Rates . . . . 42

1. Constant Bed Weight................ 42

2. Constant Number of Particles.............. 43

ACKNOWLEDGMENT . . . . . . . . . . . . . . . . . 44 


\section{LIST OF FIGURES}

No.

Title

Page

1. Schematic Drawing of Equipment for Fluid-bed Hydrolysis of Uranium Hexafluoride to Uranyl Fluoride . . . . . . . .

2. Schematic Drawing of Equipment for Fluid-bed Reduction of Uranyl Fluoride to Uranium Dioxide............

3. Uranyl Fluoride Particles Produced by Fluid-bed Hydro-

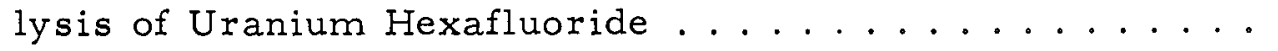

4. Sectioned Uranyl Fluoride Particles .............. 14

5. Particle Size Behavior during Fluid-bed Hydrolysis with Seed Addition. .................... 16

6. Particle Size Behavior during 25- and 50-Hour Fluid-bed Hydrolysis Runs. . . . . . . . . . . . . . . . .

7. The Effect of Gas Composition on the Removal of Fluoride with Respect to Reaction Time ............. 24

8. Uranium Dioxide Product Showing Hull-shaped Fragments. . 30

9. Uranium Dioxide Sample Showing Particle Voids ....... 30

10. Dense Uranium Dioxide Particles as Produced in the

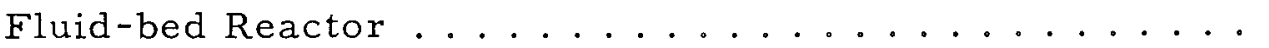

11. Cross Section of Dense Uranium Dioxide Particles Showing

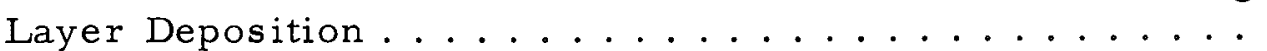

12. Cross Section of Dense Uranium Dioxide Particle Showing

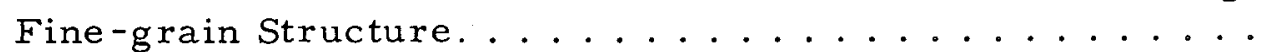

13. Cross Section of Dense Uranium Dioxide Particle after Sintering in Hydrogen at $1700 \mathrm{C} \ldots \ldots \ldots$ 


\section{LIST OF TABLES}

No.

Title

$\underline{\text { Page }}$

1. Preliminary Uranium Hexafluoride Hydrolysis Runs. . . . . . 12

2. Uranium Hexafluoride Hydrolysis - Operation with Seed

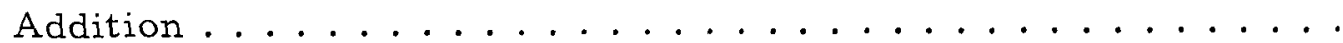

3. Nominal Operating Conditions for Extended-length Hexafluoride Hydrolysis Runs. . . . . . . . . . . . . . .

4. Typical Properties of Uranyl Fluoride Product . . . . . . . . 18

5. High-temperature Hydrolys is of Uranium Hexafluoride . . . . . 20

6. Particle Size Effects during Hydrolysis Noted as a Function of Starting Bed Particle Size ................ 21

7. Summary of Range of Operating Variables Evaluated in the Fluid-bed Reduction of Uranyl Fluoride to Uranium Dioxide. . .

8. Results of the Conversion of Uranyl Fluoride to Uranium Dioxide with Hydrogen-Steam Mixtures.............

9. Results of the Reduction of Uranyl Fluoride to Uranium Di-

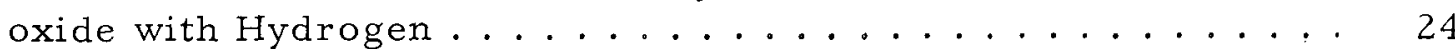

10. The Effect of Gas Velocity on the Conversion of Uranyl Fluoride to Uranium Dioxide . . . . . . . . . . . . 26

11. The Effect of Temperature on the Conversion of Uranyl Fluo-

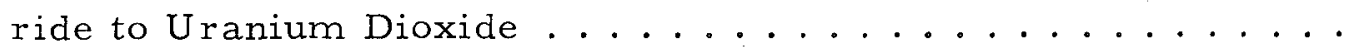

12. Results of the Bed-depth Study on the Conversion of Uranyl

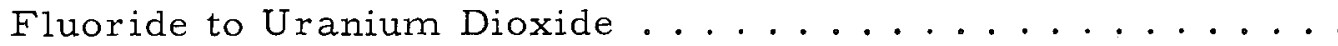

13. The Effect of Feed Particle Size on the Conversion of Uranyl Fluoride to Uranium Dioxide ................

14. Results of Pellet Fabrication Experiments on Uranium Dioxide Prepared by Fluid-bed Conversion of Uranium Hexafluoride . .

15. Summary of Sintering Tests Performed on Uranium Dioxide Prepared by Simultaneous Reaction of Uranium Hexafluoride with Steam and Hydrogen. . . . . . . . . . . . . .

16. Results of Sintering Tests on Dense Uranium Dioxide Particles Produced in the Fluid-bed by the Simultaneous Reaction Procedure. $\cdot \cdot \cdot \cdot \cdot \cdot \cdot \cdot \cdot \cdot \cdot \cdot \cdot \cdot \cdot \cdot \cdot \cdot \cdot \cdot \cdot \cdot \cdot \cdot \cdot \cdot \cdot \cdot \cdot \cdot \cdot \cdot$

17. Identification of Types of Uranyl Fluoride Formed by Gas phase Reaction of Uranium Hexafluoride and Steam ....... 


\title{
A FLUID-BED PROCESS FOR THE DIRECT CONVERSION OF URANIUM HEXAFLUORIDE TO URANIUM DIOXIDE
}

\author{
by
}

I. E. Knudsen, H. E Hootman, and N. M. Levitz

\section{ABSTRACT}

A new, dry process for the production of uranium dioxide powder from uranium hexafluoride by fluidization and particle-coating techniques has been developed. The process involves direct conversion of uranium hexafluoride to a solid, uranyl fluoride, by hydrolysis with steam and the reduction of the uranyl fluoride to the dioxide by reaction with steam-andhydrogen mixtures. Development work on the process was carried out in 3 -in.-diameter Monel reactors.

The uranium hexafluoride-steam reaction was carried out continuously at relatively low temperatures, about $200 \mathrm{C}$, at rates equivalent to $174 \mathrm{lb}$ uranium/(hr)(sq ft reactor cross section). Nominal operating conditions during hydrolysis runs included a superficial gas velocity of $0.75 \mathrm{ft} /$ sec, an $8-\mathrm{kg}$ bed of uranyl fluoride, equivalent to about a $20-\mathrm{in}$. static bed height, and a seed particle (uranyl fluoride) addition rate of $0.9 \mathrm{~kg} / \mathrm{hr}$. Seed addition was required to offset particle growth effects, i.e., to maintain a uniform average particle size throughout the run. Demonstration hydrolysis runs of up to 50-hr duration were made. Uranium losses to the off-gas were negligible, and were equivalent to about 0.01 percent of the hexafluoride feed.

Reduction of the uranyl fluoride to the oxide was demonstrated in batch tests. Production of low-fluoride $(<250 \mathrm{ppm})$ material in experiments which utilized up to $9-\mathrm{kg}$ beds was consistently achieved in $4 \mathrm{hr}$ at 650 . C and in $7 \mathrm{hr}$ at 600 C with a.50-50 mixture of steam and hydrogen. More rapid rates of conversion were achieved by utilizing (1) mixtures of steam and hydrogen instead of hydrogen alone, (2) smaller particles (in the range 40 to 60 mesh as compared with 20 to 40 mesh size) and (3) higher gas velocities (about $2.0 \mathrm{ft} / \mathrm{sec}$ ) whereby greater quantities of reactants per unit time were introduced. No apparent effect on conversion rate was noted when the bed depthwas varied (in the range from 8 to 23 in.). Pellet fabrication tests with dioxide powders ground to -325 mesh gave, after sintering, densities of about 95 percent theoretical.

In continuing studies, dense, spheroidal uranium dioxide particles in the range $-20+200$ mesh are being prepared. A simultaneous (steam and hydrogen) reaction procedure at temperatures up to $700 \mathrm{C}$ is being used. Particle densities ranged to $9.75 \mathrm{~g} / \mathrm{cc}$ or about 89 percent of theoretical. Sintering in hydrogen at about $1700 \mathrm{C}$ for $2.5 \mathrm{hr}$ gave final densities of 10.4 to $10.6 \mathrm{~g} / \mathrm{cc}$ or up to about 96.5 percent of theoretical density. 


\section{INTRODUCTION}

The use of uranium dioxide as a fuel in nuclear reactors is increas ing because of its physical and chemical properties, such as inertness to cooling media, irradiation stability, and good retention of fission gas. These properties make the dioxide well suited for application in both bulk and dispersion forms. The dioxide is relatively easy to prepare and to fabricate into desired shapes, and it is amenable to chemical reprocessing after ir radiation. With the growth of the nuclear power field, reduced costs of preparation should provide added incentive for further application of the oxide as fuel material.

The currently employed ADU process(1) for the conversion of uranium hexafluoride to uranium dioxide is primarily a batch operation involving aqueous precipitation, filtration, drying, calcination, and reduction steps. Preliminary work at ANL(2) demonstrated the feasibility of applying fluidization techniques to this conversion. Reduced costs are expected to result from the use of fluid-bed techniques because these techniques offer inherent simplicity of process equipment, advantageous heat transfer, and improved solids -handling characteristics.

Studies were made of alternative reaction schemes, whichincluded simultaneous reaction of uranium hexafluoride with steam and hydrogen, and separate reactions in which the hexafluoride was initially reacted with steam to produce uranyl fluoride and the uranyl fluoride was then reduced to the dioxide by reaction with mixtures of hydrogen and steam. A practical process scheme for the production of dioxide was developed for the separate reaction procedure. The production of uranyl fluoride was carried out continuously and the reduction to the oxide was carried out batchwise. Process chemistry details and development studies leading to the final fluid-bed process are presented below.

\section{PROCESS CHEMISTRY}

\section{A. Process Reactions}

The preliminary fluid-bed work on a direct conversion process $(2)$ for preparing uranium dioxide from uranium hexafluoride was based on a simultaneous reaction scheme in which complete conversion to the dioxide was attempted in a single step as represented by the reaction:

$$
\mathrm{UF}_{6}(\mathrm{~g})+\mathrm{H}_{2}(\mathrm{~g})+2 \mathrm{H}_{2} \mathrm{O}(\mathrm{g}) \rightarrow \mathrm{UO}_{2}(\mathrm{~s})+6 \mathrm{HF}(\mathrm{g}) ; \Delta \mathrm{H}_{298 \mathrm{C}}=-23.4 \mathrm{kcal} / \mathrm{mole}
$$

This overall reaction depends upon several intermediate reactions. The hexafluoride may react with either the steam or the hydrogen: 
$\mathrm{UF}_{6}(\mathrm{~g})+2 \mathrm{H}_{2} \mathrm{O}(\mathrm{g}) \rightarrow \mathrm{UO}_{2} \mathrm{~F}_{2}(\mathrm{~s})+4 \mathrm{HF}(\mathrm{g}) ; \Delta \mathrm{H}_{298 \mathrm{C}}=-26.8 \mathrm{kcal} / \mathrm{mole}$

$\mathrm{UF}_{6}(\mathrm{~g})+\mathrm{H}_{2}(\mathrm{~g}) \rightarrow \mathrm{UF}_{4}(\mathrm{~s})+2 \mathrm{HF}(\mathrm{g}) ; \Delta \mathrm{H}_{298 \mathrm{C}}=-67.4 \mathrm{kcal} / \mathrm{mole}$.

To form the dioxide, the uranyl fluoride produced (Reaction 2) may then be reacted as follows:

$\mathrm{UO}_{2} \mathrm{~F}_{2}(\mathrm{~s})+\mathrm{H}_{2}(\mathrm{~g}) \rightarrow \mathrm{UO}_{2}(\mathrm{~s})+2 \mathrm{HF}(\mathrm{g}) ; \Delta \mathrm{H}_{298 \mathrm{C}}=+3.4 \mathrm{kcal} / \mathrm{mole}$

or

$\mathrm{UO}_{2} \mathrm{~F}_{2}(\mathrm{~s})+\mathrm{H}_{2} \mathrm{O}(\mathrm{g}) \rightarrow \frac{1}{3} \mathrm{U}_{3} \mathrm{O}_{8}(\mathrm{~s})+2 \mathrm{HF}(\mathrm{g})+\frac{1}{6} \mathrm{O}_{2} ; \Delta \mathrm{H}_{298 \mathrm{C}}=-36.6 \mathrm{kcal} / \mathrm{mole}$

followed by

$\frac{1}{3} \mathrm{U}_{3} \mathrm{O}_{8}(\mathrm{~s})+\frac{2}{3} \mathrm{H}_{2}(\mathrm{~g}) \rightarrow \mathrm{UO}_{2}(\mathrm{~s})+\frac{2}{3} \mathrm{H}_{2} \mathrm{O}(\mathrm{g}) ; \Delta \mathrm{H}_{298 \mathrm{C}}=-13.7 \mathrm{kcal} / \mathrm{mole}$.

Alternatively, the uranium tetrafluoride produced (Reaction 3) may be pyrohydrolyzed with steam as follows:

$\mathrm{UF}_{4}(\mathrm{~s})+2 \mathrm{H}_{2} \mathrm{O}(\mathrm{g}) \rightarrow \mathrm{UO}_{2}(\mathrm{~s})+4 \mathrm{HF}(\mathrm{g}) ; \Delta \mathrm{H}_{298 \mathrm{C}}=+44.0 \mathrm{kcal} / \mathrm{mole}$.

The heats of reaction were calculated from the data of Glassner(3) and Popov. (4) In the current work, consideration was given to the separation of the reactions into two process steps. In this scheme, the hexafluoride would be reacted initially to produce the solids shown in Eqs. (2) and (3). The solids would then be converted to the dioxide in a second reactor. This procedure appeared to offer increased flexibility in choice of reactor conditions and process control.

\section{B. Literature Review}

\section{Uranium Hexafluoride Reactions}

The vapor-phase hydrolysis of uranium hexafluoride to uranyl fluoride occurs readily with exposure to moisture. A deposit of white or yellow material is formed and, with larger quantities, a white smoke is seen. Katz ${ }^{(5)}$ cites early British work in which the reaction with water vapor was found to give a. complex of uranyl fluoride, hydrogen fluoride, and water. More recently, scouting studies of the vapor-phase hydrolysis reaction were carried out at the Oak Ridge Gaseous Diffusion Plant (ORGDP)(6) and at the National Lead Company $(\mathrm{NLCO})(7)$ in 4 - to 10 -in.-diameter vertical-tube reactors. 
At ORGDP, application of this reaction to the conversion of stored depleted uranium hexafluoride to a more conveniently stored powder form was being considered. At $\mathrm{NLCO}$, the intent was to produce a uranyl fluoride product with high surface area which could be readily reduced to uranium dioxide. In both cases, the work was conducted at $350 \mathrm{~F}$; the uranyl fluoride produced was extremely light and fluffy, having, in one case, a packed density of only $0.24 \mathrm{~g} / \mathrm{cc}$.

Uranium hexafluoride reduction by hydrogen to the tetrafluoride has been applied to production use by Smiley and Brater(8) at ORGDP in their development of the tower reduction process. The reaction with hydrogen has a high activation energy and is highly exothermic. The reactants were preheated to $500 \mathrm{~F}$ and reacted rapidly in the reactor, which was held at $1000 \mathrm{~F}$. The tetrafluoride product was of high density and purity. A small amount of intermediate fluoride compounds of uranium formed on the walls when heat was supplied in this way. An alternative method, which succeeded in eliminating deposition of solids on the walls, involved introduction of fluorine with the hexafluoride. The exothermic hydrogen-fluorine reaction supplied the necessary heat for the reduction reaction. Under these conditions, the reactor walls could be held at temperatures as low as $300 \mathrm{~F}$. Previous work(9) generally had been unsuccessful in achieving quantitative reaction, even with the use of catalysts.

\section{Intermediate-compound Reactions}

The kinetics of the hydrogen reduction of uranyl fluoride to the oxide were studied by Kuhlman(10) by means of a thermobalance in the temperature range from 450 to $700 \mathrm{C}$. A pronounced temperature effect on the rate of reaction was found. Kuhlman also found that hydrofluorination of the oxide occurred, but observed that the hydrogen fluoride did not inhibit the reduction reaction as it did in the case of the reduction of uranium trioxide. Ferris and Gardner(ll) carried out a similar thermogravimetric study associated with the Fluorox process and found the formation of the tetrafluoride to be negligible at $700 \mathrm{C}$. They suggest that the greater bed depth $(\sim 5 \mathrm{~mm})$ used by Kuhlman may account for the formation of the tetrafluoride. The rate of reduction was found to be sufficiently high for the application to the Fluorox process, but numerical values were not obtained. Katz (12) reports that workers found that the reaction was rapid at $600 \mathrm{C}$ and that the product obtained was very reactive.

The hydrolysis of uranyl fluoride has not been investigated as a separate study. At ORGDP, however, in a study (13) of the recovery of fluoride from depleted uranium hexafluoride, pyrohydrolysis of the hexafluoride at $1500 \mathrm{~F}$ with steam excesses of 43 percent gave an oxide product with less than one percent fluoride. Approximately 90 percent of the total fluoride was recovered. Thermal decomposition of uranyl fluoride also becomes significant at these temperatures. (14) Reduction of $\mathrm{U}_{3} \mathrm{O}_{8}$ to the dioxide with hydrogen occurs readily at temperatures below 650 C. $(15,16)$ 
The hydrolysis of uranium tetrafluoride is the basis of an analytical method for the determination of fluoride; (17) steam is passed over the material at $1000 \mathrm{C}$ and the hydrofluoric acid solution is collected and titrated. This reaction is also utilized in the "reversion" of offspecification tetrafluoride to oxides (18) prior to processing by solvent extraction. In fluid-bed tests made at Argonne National Laboratory, (2) about 99 percent conversion of the tetrafluoride to the dioxide was achieved in $1.5 \mathrm{hr}$ at bed temperatures of 650 to $675 \mathrm{C}$.

\section{APPARATUS AND PROCEDURE}

The hexafluoride-conversion unit is shown schematically in Fig. 1; a unit of similar design but with the filter vessel as an integral part of the column (see Fig. 2) was used in the batch reduction tests. Most of the

Figure 1
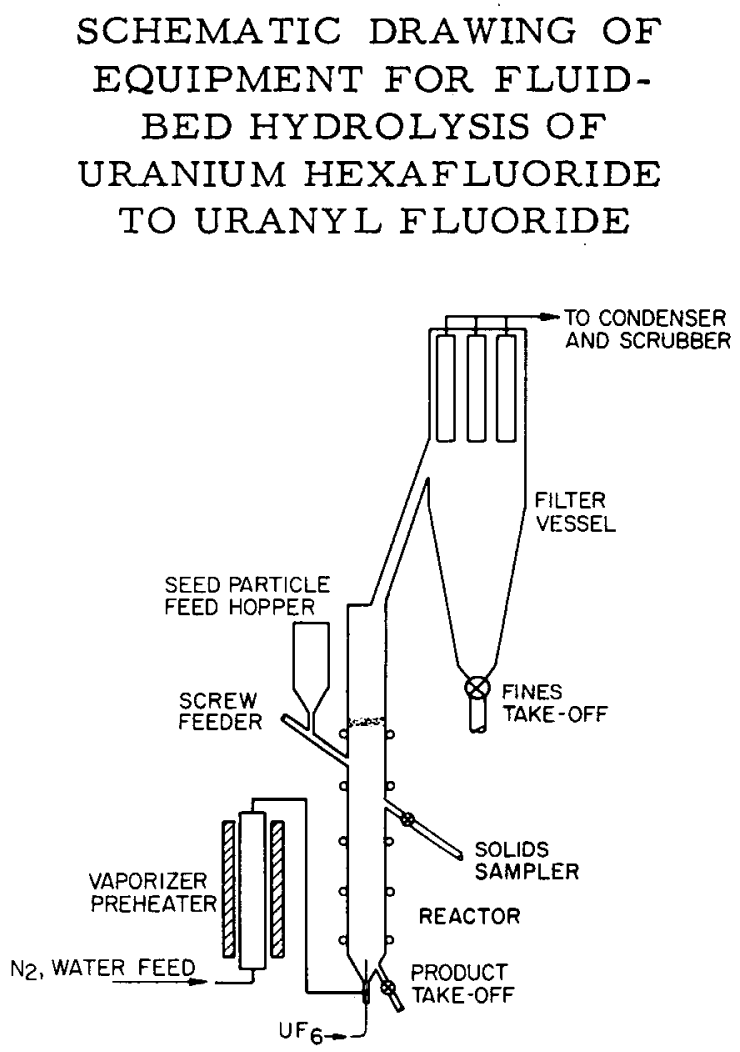

$108-4654$ description below of the hydrolysis equipment also pertains to the reduction equipment except for those items which are associated with continuous flow of solids and hexafluoride feed. The hydrolysis column was of 3 -in.-diameter Schedule $40 \mathrm{Monel}$ pipe, 30 in. high, and had a $60^{\circ}$ cone bottom. The column was wrapped with sheather tubular electrical heaters. A $\frac{1}{4}$-in.-OD tube which passed through the apex of the cone bottom and extended into the bed served as the nozzle for uranium hexafluoride feed. An annulus around this nozzle provided for entrance of the fluidizing and/or reactant gases. A solids-recycle line for the addition of seed particles was provided at a point 20 in. up the column. A sample tap for solids was located at a point about 3 in. below the solids recycle line. Product was withdrawn from an outlet located at the bottom of the cone. Thermocouples and pressure taps were located at various heights along the column.

The filter vessel was $30 \mathrm{in.} \mathrm{high,} 8 \mathrm{in}$. in diameter, and tapered to 3 in. in diameter at the bottom. It was fabricated of 16-gauge Monel sheet. A one-inch line which connected the reactor and filter vessels entered the side of the filter vessel at a point 10 in. from the top. The line made an 
angle of $20^{\circ}$ from the vertical. Three porous metal bayonet filters, 3 in. wide and $9 \mathrm{in.}$ long, were mounted in the top flange. An automatic jetpulse blowback system, which utilized 80-psig nitrogen, discharged accumulated solids from the filters to the lower part of the filter vessel, where the solids were periodically withdrawn.

Figure 2
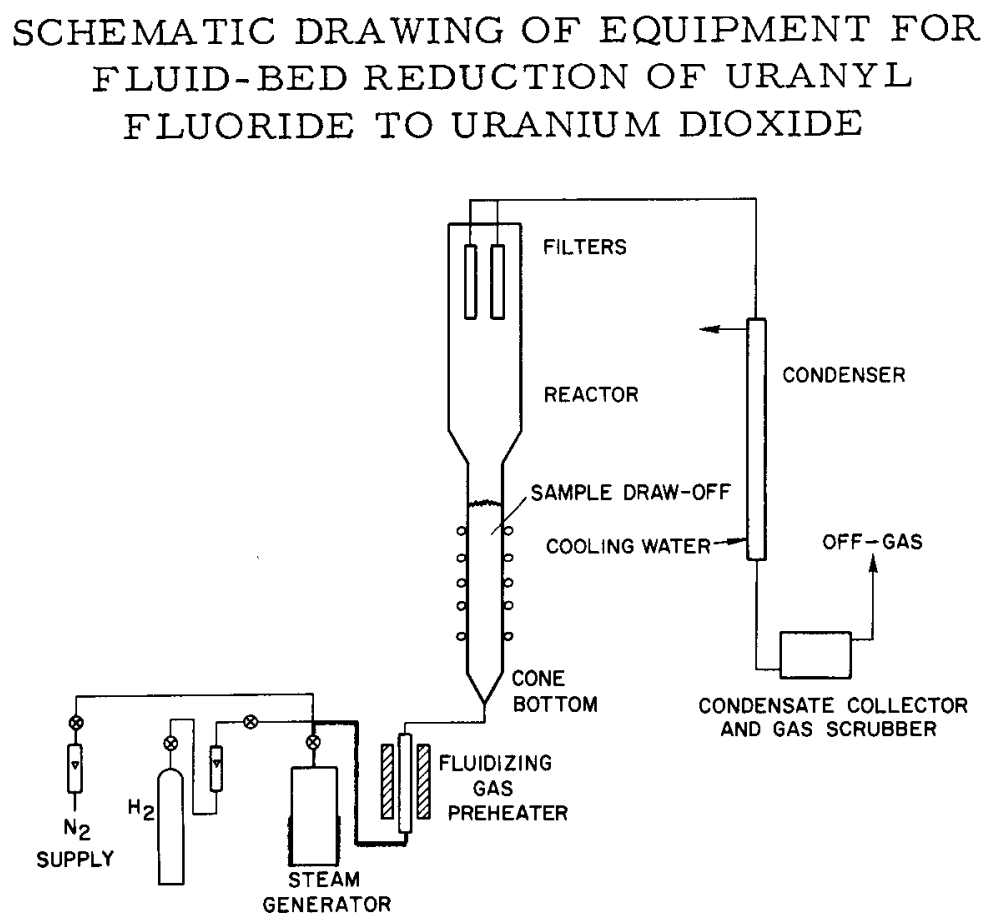

$108-5722$

The off-gas passed to a Monel condenser. Condensate was collected in plastic receivers. The noncondensable gases were scrubbed in a circulating caustic scrubber which consisted of a packed 6-in.-diameter tower, $8 \mathrm{ft}$ high. Condensate and caustic samples were analyzed to estimate uranium losses.

Nitrogen at 35 psig was used for line purges and for bed fluidization during startup and shutdown. Process steam was generated by metering distilled water from a calibrated feed tank into a vaporizer-preheater. The hexafluoride was fed from an electrically heated cylinder that was mounted on a scale and had flexible connections to permit continuous weighing. Cylinders containing up to $400 \mathrm{lb}$ of uranium hexafluoride were used. The feed rate was metered by an orifice which actuated a control valve (Research Controls,* Type 1279 MS, Monel sealing bellows) through a Taylor**

* Research Controls, Tulsa, Oklahoma.

** Taylor Instrument Company, Rochester, New York. 
differential pressure transmitter (Type 339R, phosphor-bronze measuring bellows) and Taylor Miniature recorder-controller (Transcope recorder, Type 91J243; Tri-Scope controller, Type 414RF 1043).

Run procedure involved starting of the nitrogen purge and fluidizing gas streams before charging of the starting bed. The bed was then charged while the column was maintained at a slight negative pressure by use of an air ejector. This procedure minimized dusting. Filter blowback was started immediately after the bed had been charged.

Steam was introduced and the flow of fluidizing nitrogen stopped shortly after the bed temperature exceeded $100 \mathrm{C}$. When operating conditions were reached and stabilized, hexafluoride feed was introduced. Product take-off was controlled by automatic operation of a plug valve, actuated by a Pressuretrol which sensed the bed weight. Fines which accumulated in the filter vessel were withdrawn periodically. Temperature, pressure, and feed-rate readings were recorded periodically, and bed samples taken as desired.

Continuous operation of the hydrolysis column over extended periods of time required the addition of seed particles to offset the overall growth of the bed particles, which was caused by deposition of newly formed material on the particle surfaces. The starting bed consisted of $-20+200$ mesh particles and $-60+200$ mesh material was used as seed. The major part of the seed-recycle stream could be obtained from the product stream, but some grinding of coarse material was required to obtain adequate quantities of seed material. Seed was added by a screw feeder through a downwardsloped line which was purged with nitrogen. This material entered several inches below the top of the bed. Seed particle addition was usually started immediately after the hexafluoride feed was introduced. 


\section{PROCESS DEVELOPMENT STUDIES}

The two-step process, i.e., hydrolysis of the hexafluoride to uranyl fluoride followed by reduction of the uranyl fluoride to the dioxide, was studied in detail in separate reactors. Experimental work on the hydrolysis step was directed toward demonstration of continuous operation. The effects of process variables were investigated to establish a range within which good operation could be maintained. The reduction of uranyl fluoride to the dioxide was studied in a batch system to determine the optimum timetemperature cycle for the production of low-fluoride material. Reactant gas composition, particle size, bed height, and superficial velocity were studied for effects on the reduction reaction.

A. Results and Discussion of the Fluid-bed Hydrolysis of Uranium Hexafluoride to Uranyl Fluoride

The preparation of uranyl fluoride by the hydrolysis of uranium hexafluoride with steam was demonstrated in a 3-in.-diameter fluid-bed reactor in continuous runs of up to $50-\mathrm{hr}$ duration. The preliminary work on the hydrolysis was carried out first in a series of short-duration runs in which the bed temperature and hexafluoride feed rate were varied. Subsequently, longer runs were made to investigate further the effect of process variables.

\section{Preliminary Hydrolysis Work}

Runs of 1.5 - to 3.0-hr duration were made in the 3-in.diameter fluid-bed reactor to explore briefly the uranium hexafluoridesteam reaction. The operating conditions and particle growth rates are summarized in Table l. Starting beds consisted of 7 to $8.5 \mathrm{~kg}$ of uranyl

Table 1

\section{PRELIMINARY URANIUM HEXAFLUORIDE HYDROLYSIS RUNS}

Equipment: Starting Bed:

Steam Superficial Velocity: 3-in.-diameter Monel fluid-bed columna

7 to $8.5 \mathrm{~kg}$ of uranyl fluoride; 18 to

20 in., static height

$0.75 \mathrm{ft} / \mathrm{sec}$

\begin{tabular}{|c|c|c|c|c|c|c|}
\hline \multirow[b]{2}{*}{$\begin{array}{l}\text { Run } \\
\text { No. }\end{array}$} & \multirow[b]{2}{*}{$\begin{array}{l}\text { Temp } \\
\text { (C) }\end{array}$} & \multirow[b]{2}{*}{$\begin{array}{c}\mathrm{UF}_{6} \\
\text { Rate } \\
(\mathrm{g} / \mathrm{min})\end{array}$} & \multirow[b]{2}{*}{$\begin{array}{c}\text { Steam } \\
\text { Excess } \\
(\%)\end{array}$} & \multirow[b]{2}{*}{$\begin{array}{c}\text { Run } \\
\text { Duration } \\
\text { (hr) }\end{array}$} & \multicolumn{2}{|c|}{$\begin{array}{c}\text { Average Particle } \\
\text { Size }(\mu)\end{array}$} \\
\hline & & & & & $\begin{array}{l}\text { Starting } \\
\text { Bed }\end{array}$ & $\begin{array}{c}\text { Final } \\
\text { Bed }\end{array}$ \\
\hline 39 & 230 & 66 & 390 & 2.7 & 207 & 297 \\
\hline 40 & 230 & 118 & 175 & 2.5 & 179 & 389 \\
\hline 43 & 200 & 111 & 190 & 1.5 & 185 & 99 \\
\hline $44 \mathrm{~A}$ & 140 & 78 & 310 & 1.9 & 231 & 322 \\
\hline
\end{tabular}

a These tests were made in a reactor with an integral filter vessel similar to that shown in Fig. 2 . 
fluoride. Bed temperatures ranged from 140 to $230 \mathrm{C}$, and the hexafluoride feed rate ranged from 66 to $118 \mathrm{~g} / \mathrm{min}$, the latter value being equivalent to $205 \mathrm{lb}$ uranium $/(\mathrm{hr}$ ) (sq ft reactor cross section). Since this reaction is exothermic, cooling of the reactor was required at the higher feed rates to maintain bed temperatures below $200 \mathrm{C}$. At the lower temperature $(140 \mathrm{C})$, problems associated with condensation of steam were encountered, although these could probably be eliminated by more extensive heat-tracing and insulation of equipment. Losses of uranium from the system as determined by analysis of the off-gas scrub solution were negligible. The losses corresponded to 0.01 percent of the hexafluoride feed rate.

Particle growth rates for Runs 39, 40, and 44A ranged from 33 to $84 \mu / \mathrm{hr}$. These values agree with 10 percent of calculated average values (see Appendix, page 42), using as a basis, 100 percent deposition of uranyl fluoride on the particles of the bed. In Run 43, extensive fines formation occurred, resulting in an overall decrease in average bed particle size (see section on particle size effects, page 2l).

The uranyl fluoride product was bright yellow and the particles appeared to have a glazed surface (see Fig. 3). Growth rings were not readily apparent in sectioned particles (see Fig. 4), although such rings

\section{Figure 3}

\section{URANYL FLUORIDE PARTICLES PRODUCED BY FLUID- BED HYDROLYSIS OF URANIUM HEXAF LUORIDE}

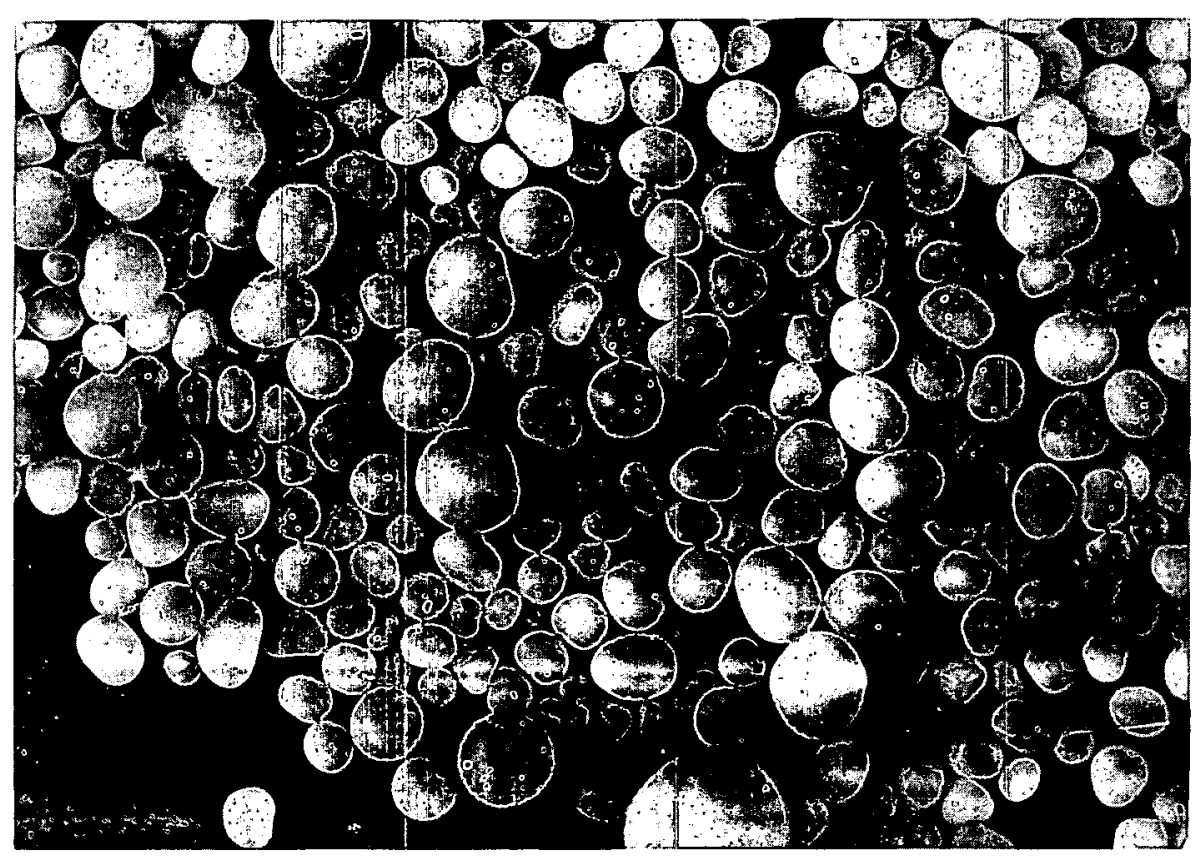

$-20+200$ Mesh Particles

(Magnification - 23X) 
Figure 4

SECTIONED URANYL FLUORIDE PARTICLES

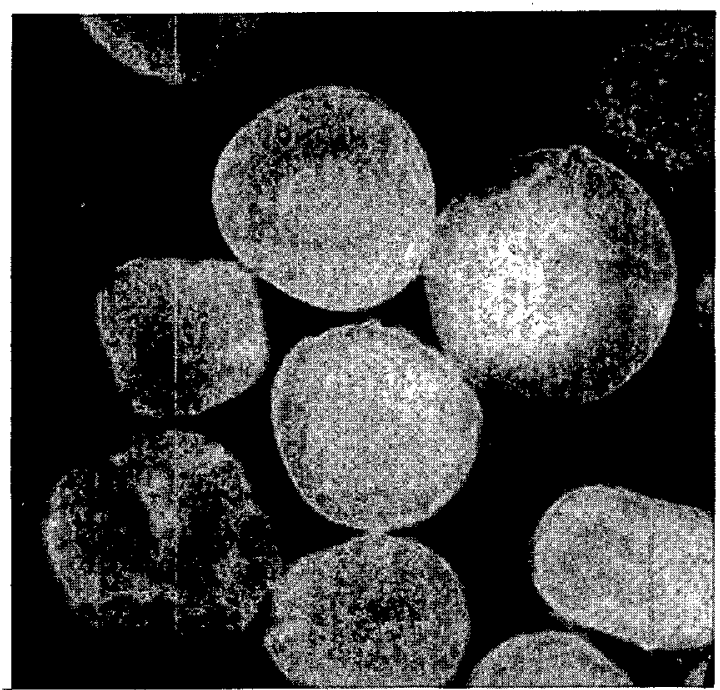

(Magnification - 40X)

were observed in other studies. (2) In some samples, the outer layer of the particle appeared translucent and was similar to coatings noted by workers at BMI in studies in which particles were coated with beryllia. (19) The bulk density of the uranyl fluoride product was about $3.5 \mathrm{~g} / \mathrm{cc}$. Material produced at $230 \mathrm{C}$ was found to have a smaller surface area than that produced at $140 \mathrm{C}$; typical values of the surface areas were 0.18 and $0.42 \mathrm{sq} \mathrm{m} / \mathrm{g}$, respectively.

The results of this work indicated that the hydrolysis reaction occurred primarily on the surface of the uranyl fluoride particles which comprise the bed. A small portion of the hexafluoride also reacted in the gas phase to form fines which could serve as seed particles. The growth rates, however, indicated that additional seed particles would be required to maintain a uniform average particle size in the bed. Feeding of a sidestream of seed particles was therefore incorporated into the normal operating procedure, which is described below.

\section{Hydrolysis Studies with Particle Recycle}

Further tests of the hydrolysis step were made at 200 to $230 \mathrm{C}$ with additions of seed particles to offset particle growth (see Table 2). The durations of the runs were as long as $19 \mathrm{hr}$. The hexafluoride rate was held constant at $100 \mathrm{~g} / \mathrm{min}$. The weight of the starting bed of uranyl fluoride was 7 to $8 \mathrm{~kg}(18$ - to 20 -in. static bed height). The particle size distribution in the starting bed was $-20+200$ mesh with 
average particle diameters ranging from 260 to $334 \mu$. This material was somewhat coarser than that used in the initial runs (see Table 1). The seed particles were $-60+200 \mathrm{mesh}$, with an average size of $160 \mu$. The seed addition rate averaged 14 percent by weight of the hexafluoride feed rate. Under these conditions, bed turnover time was about $1.4 \mathrm{hr}$.

Table 2

URANIUM HEXAFLUORIDE HYDROLYSIS OPERATION WITH SEED ADDITION

Equipment: $\quad 3$-in.-diameter Monel column

Temperature: 200 to $230 \mathrm{C}$

$\mathrm{UF}_{6}$ Feed Rate: $100 \mathrm{~g} / \mathrm{min}$

Starting Bed: 7 to $8 \mathrm{~kg}$ of uranyl fluoride; 18 to $20 \mathrm{in.,}$ static height

\begin{tabular}{|c|c|c|c|c|c|c|}
\hline $\begin{array}{l}\text { Run } \\
\text { No. }\end{array}$ & $\begin{array}{c}\text { Steam } \\
\text { Excess } \\
(\%) \\
\end{array}$ & $\begin{array}{c}\text { Run } \\
\text { Dura - } \\
\text { tion } \\
(\mathrm{hr}) \\
\end{array}$ & $\begin{array}{c}\text { Steam } \\
\text { Superficial } \\
\text { Velocity } \\
(\mathrm{ft} / \mathrm{sec}) \\
\end{array}$ & $\begin{array}{c}\text { Seed } \\
\text { Addition } \\
\text { Rate } \\
(\text { as w/o } \\
\mathrm{UF}_{6} \text { Fed) } \\
\end{array}$ & $\begin{array}{l}\text { Average } \\
\text { Bed } \\
\text { Particle } \\
\text { Size }(\mu) \\
\end{array}$ & $\begin{array}{c}\text { Carryover } \\
\text { (as w/o } \\
\mathrm{UF}_{6} \text { Fed) } \\
\end{array}$ \\
\hline 62 & 225 & 4.5 & 0.75 & 15 & 316 & 5.2 \\
\hline $62 \mathrm{~A}$ & 225 & 7.5 & 0.75 & 14 & 320 & 2.4 \\
\hline $62 B$ & 225 & 4.2 & 0.75 & 17 & 323 & 1.1 \\
\hline $62 C$ & 225 & $19.3^{\mathrm{a}}$ & 0.75 & 14 & 310 & 5.0 \\
\hline $62 \mathrm{D}$ & 115 & 7.5 & 0.50 & 14 & 308 & 5.3 \\
\hline $62 \mathrm{E}$ & 325 & 12.0 & 1.0 & 14 & 327 & 6.3 \\
\hline $62 F$ & 115 & 11.6 & 0.50 & 24 & 280 & 7.4 \\
\hline
\end{tabular}

aRun was interrupted by plugging of one-inch line connecting filter and reactor vessels after $4 \mathrm{hr}$ of hexafluoride feed; operation was resumed 2 hr later.

Operational stability was very good in these tests. Average bed particle size remained within good operational limits of 250 to $350 \mu$ throughout the $66 \mathrm{hr}$ of accumulated run time (see Fig. 5). Changes in the superficial velocity (in the range from 0.5 to $1.0 \mathrm{ft} / \mathrm{sec}$ ) did not appear to have a marked effect on average bed particle size. The carryover (elutriation) of uranyl fluoride fines to the filter vessel correspond to 1.1 to 7.4 percent of the feed. In general, lower carryover was associated with coarser beds. The effect of changes in the seed addition rate was shown by sieve analysis of grab samples. Typically, a 70 percent increase in seed addition from about $840 \mathrm{~g} / \mathrm{hr}$ to about $1400 \mathrm{~g} / \mathrm{hr}$ in Run $62 \mathrm{~F}$ caused a 25 percent reduction in average bed particle size over a 10 -hr period. Return to the initial rate of seed addition permitted rapid particle growth and, within $1 \frac{1}{2} \mathrm{hr}$, the original average bed particle size was approached. 
Figure 5

PARTICLE SIZE BEHAVIOR DURING

FLUID-BED HYDROLYSIS WITH SEED ADDITION

Steam Superficial Velocity: $0.75 \mathrm{ft} / \mathrm{sec}$ except where noted.

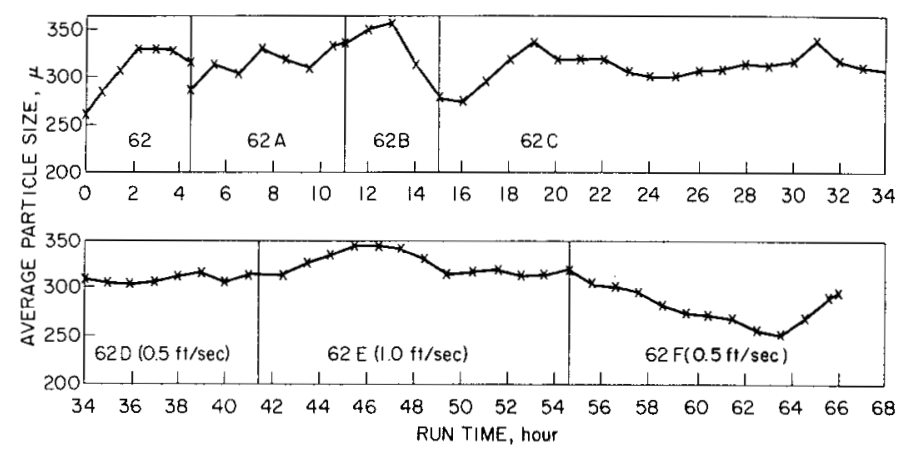

$108-5721$

Changes in the superficial velocity of the fluidizing gas (steam) affected gas-residence time and reactant excess, but these had no detectable effects on uranium losses to the off-gas. In the range studied, 115 to 335 percent steam excess and 0.5 to $1.0 \mathrm{ft} / \mathrm{sec}$ superficial gas velocity, uranium losses were consistently less than 0.01 percent of the uranium hexafluoride feed rate as determined by uranium analysis of the off-gas condensate. Further confirmation of low losses was the fact that no solids were found in the off-gas lines downstream of the porous metal filters.

\section{Demonstration Runs on the Hydrolysis Step}

Having established that satisfactory control of the particle size in the bed could be maintained within a range of seed addition rates and of superficial velocities, it remained only to demonstrate this step of the process in extended-length runs. Continuous runs of 25- and 50-hr duration were made at a hexafluoride feed rate of $100 \mathrm{~g} / \mathrm{min}$. About $400 \mathrm{~kg}$ of uranyl fluoride was produced. Operating conditions for these runs are summarized in Table 3.

Satisfactory operation was achieved, as shown graphically in Fig. 6, which is a plot of average size of bed particle as a function of run duration. The plot shows the average diameter for two samples (one from the upper portion of the bed and the other from the bottom portion of the bed). Agreement between the average particle diameters of the samples was within six to seven percent. Average particle diameter varied only \pm 10 percent from the overall average diameter $(334 \mu)$ during the $75 \mathrm{hr}$ of operation in spite of small changes in the seed-addition rate. 
Table 3

NOMINAL OPERATING CONDITIONS FOR EXTENDED-LENGTH HEXAFLUORIDE HYDROLYSIS RUNS

Equipment:

Run Duration:

Temperature:

$\mathrm{UF}_{6}$ Feed Rate:

Steam Excess:

Steam Superficial Velocity:

Starting Bed:

Seed-addition Rate:

Average Diameter of Bed Particle:a 325 to $350 \mu$

Average Diameter of Seed Particle:a $163 \mu$

aVolume/surface diameter, $D_{V s}$, calculated by the formula

$$
D_{v s}=\frac{\bar{w}}{\sum \frac{w_{i}}{d_{i}}} \text {, }
$$

where $\bar{w}=$ sum of the weight percents of solids retained on each sieve

$\mathrm{w}_{\mathrm{i}}=$ weight percent of solids retained on each sieve

$\mathrm{d}_{\mathrm{i}}=$ mean diameter of the mesh sizes of two adjacent sieves.

Figure 6

PARTICLE SIZE BEHAVIOR DURING 25 AND 50-HR FLUID-BED HYDROLYSIS

RUNS

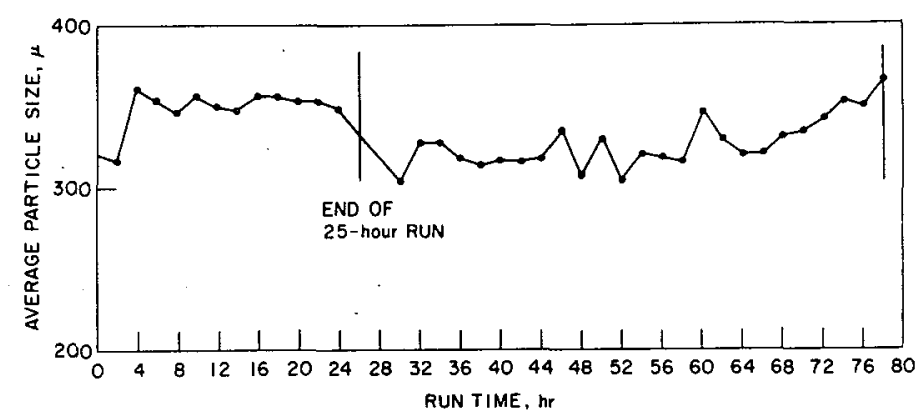

$108-5720$ 
During these long runs, fines filtration efficiency remained high. Pressure buildup across the filters was negligible, although in some earlier runs the fines layer on the filters was not removed by the pulse jet blowback system and continuous-flow blowback was required. The fines were withdrawn from the filter section with no difficulties.

A typical chemical analysis of the product and some of its physical properties are given in Table 4 . The tetravalent uranium content is typical of that found in a number of samples and may be attributed to a small amount of $\mathrm{U}_{3} \mathrm{O}_{8}$ formed either by hydrolysis or thermal decomposition of the uranyl fluoride. The low nickel content, $6 \mathrm{ppm}$, indicates that minor corrosion of the reactor occurs at these temperatures with consequent negligible contamination of the product. Particle densities [as measured by mercury displacement $(20)$ ] of up to 94 percent of theoretical were obtained with material taken from the reactor. Moisture pick-up upon exposure of the material to air resulted in the expansion of the particles and a decrease in density to 80 to 90 percent theoretical. Moisture content of exposed material was estimated from weight gains to be 0.5 to 1.5 percent; determinations by the Karl Fisher method before exposure to room atmosphere showed a moisture content of 0.016 percent. The fines fraction, averaging about 4.6 percent by weight of the hexafluoride feed, was similarly analyzed for moisture and was found to have a moisture content of 0.18 percent.

Table 4

TYPICAL PROPERTIES OF URANYL FLUORIDE PRODUCT

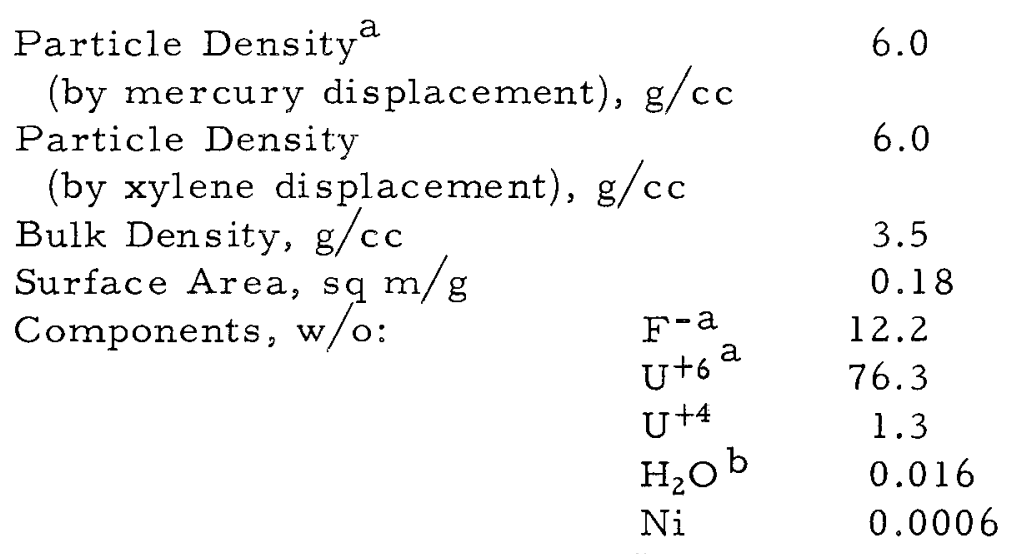

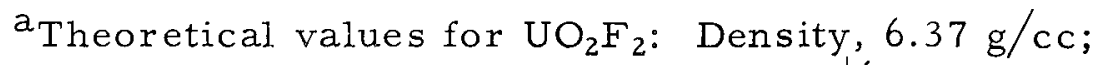
12.33 percent fluoride; 77.3 percent $U^{+6}$.

${ }^{b}$ Determined before exposure to the atmosphere.

The size distribution of the uranyl fluoride product was such that the material remained free flowing and was readily handled in subsequent fluid-bed operations. The following results were obtained in typical sieve analysis: 


\begin{tabular}{cc} 
Mesh Size & Weight Percent \\
\cline { 2 - 2 }+20 & 4 \\
+40 & 35 \\
+60 & 40 \\
+100 & 20 \\
-100 & 1
\end{tabular}

For the reduction work and other studies which are discussed below, a fraction of both the coarse and finer fractions were scalped from the bulk material. The finer material was used primarily for recycle seed stock.

4. Additional Hydrolysis Studies

a. High-temperature Hydrolysis

A possible problem associated with the hydrolysis reaction is the deposition of uranyl fluoride on internal surfaces of the reactor. Although the current deposition rates are not considered to be excessive, the rates are such that an occasional shutdown of the reactor would be required for solids removal. Two estimates of the rate of deposition, over $32.5-$ and $50-\mathrm{hr}$ periods, gave an average value of $20 \mu / \mathrm{hr}$. This solids deposition rate was about $\frac{2}{3}$ of the rate calculated on the assumption that all of the uranyl fluoride was deposited in equal thickness on the particles of the bed. Moreover, it was found that the deposition of entrained fines in the one-inch line which connects the reactor and filter vessels tended to cause an undesirable pressure buildup in the reactor.

Studies of the hydrolysis reaction at $500 \mathrm{C}$ were undertaken in an effort to eliminate the buildup of solids which occurred in operations at lower temperatures. It was anticipated that operation at a high temperature would have some effect on the characteristics of the powder, since some conversion to $\mathrm{U}_{3} \mathrm{O}_{8}$ would occur. Another incentive for the study of the hydrolysis reaction at a high temperature was the information given by Katz (21) that uranyl fluoride formed at a high temperature exhibits no deliquescence in contrast to the deliquescence of low-temperature material.

Continuous runs were made with hexafluoride feed rates of 60 and $100 \mathrm{~g} / \mathrm{min}$ with 9:1 mixtures of steam and hydrogen as well as 100 percent steam. The starting bed for this series of runs was a bed of uranyl fluoride; thereafter, the final bed from one run was used as the starting bed for the subsequent run. The work included a batch experiment (Run $65 \mathrm{C}$ ) in which the starting bed was $6 \mathrm{~kg}$ of product from Run $65 \mathrm{~B}$. Results are shown in Table 5 . 
Table 5

HIGH - TEMPERATURE HYDROLYSIS OF URANIUM HEXAFLUORIDE

\begin{tabular}{|c|c|c|c|c|c|c|c|c|c|}
\hline \multirow{3}{*}{$\begin{array}{l}\text { Run } \\
\text { No. }\end{array}$} & \multirow{3}{*}{$\begin{array}{l}\mathrm{UF}_{6} \\
\text { Feed } \\
\text { Rate } \\
(\mathrm{g} / \mathrm{min})\end{array}$} & \multicolumn{7}{|c|}{$\begin{array}{ll}\text { Equipment: } & 3 \text {-in. }- \text { di } \\
\text { Reactor Temperature: } & 500 \mathrm{C} \\
\text { Steam }-\mathrm{H}_{2} \text { Superficial Velocity: } & 0.75 \mathrm{ft} / \mathrm{s} \\
\text { Bed Height: } & 15 \text { to } 20\end{array}$} & \multirow{3}{*}{$\begin{array}{l}\text { Bulk Density } \\
-60+100 \\
\text { Mesh Fraction } \\
(\mathrm{g} / \mathrm{cc})\end{array}$} \\
\hline & & \multirow{2}{*}{$\begin{array}{l}\text { Duration } \\
\text { (hr) }\end{array}$} & \multirow{2}{*}{$\begin{array}{c}\text { Steam }-\mathrm{H}_{2} \\
\text { Ratio }\end{array}$} & \multirow{2}{*}{$\begin{array}{l}\text { Bed } \\
\text { wt } \\
(\mathrm{kg})\end{array}$} & \multirow{2}{*}{$\begin{array}{l}\text { Solids } \\
\text { Residence } \\
\text { Time } \\
\text { (hr) }\end{array}$} & \multicolumn{3}{|c|}{$\begin{array}{l}\text { Final Product } \\
\text { Analyses }(w / 0)\end{array}$} & \\
\hline & & & & & & $\mathrm{F}^{-}$ & $U^{+4}$ & $\mathrm{U}^{\text {Total }}$ & \\
\hline $65 C^{a}$ & - & 3.0 & Steam Only & 6.0 & - & 0.4 & 29.8 & 83.3 & 3.0 \\
\hline $65 \mathrm{~A}$ & 100 & 1.5 & $9: 1$ & 3.9 & 0.7 & 10.8 & 1.4 & 78.5 & 3.1 \\
\hline $65 B$ & 100 & 2.0 & $9: 1$ & 4.9 & 0.9 & $\begin{array}{l}5.8 \\
9.4 b\end{array}$ & $\begin{array}{l}23.3 \\
29.3^{b}\end{array}$ & $\begin{array}{l}78.6 \\
80.4^{b}\end{array}$ & 2.7 \\
\hline $65 \mathrm{D}$ & 60 & 5.0 & Steam Only & 3.1 & 1.0 & $\begin{array}{l}12.0 \\
12.1 \mathrm{~b}\end{array}$ & $\begin{array}{l}6.9 \\
7.1 \mathrm{~b}\end{array}$ & $\begin{array}{l}78.0 \\
76.8^{b}\end{array}$ & 2.3 \\
\hline $65 \mathrm{E}$ & 60 & 6.0 & $9: 1$ & 2.8 & 0.9 & $\begin{array}{c}8.6 \\
12.5^{b}\end{array}$ & $\begin{array}{l}21.7 \\
1.1 \mathrm{~b}\end{array}$ & $\begin{array}{l}80.1 \\
76.3^{b}\end{array}$ & 3.1 \\
\hline
\end{tabular}

a Batch run; others continuous-feed runs.

bFines collected in filter vessel.

Extensive conversion of the uranyl fluoride to $\mathrm{U}_{3} \mathrm{O}_{8}$ was achieved in the $3-\mathrm{hr}$ batch test (Run $65 \mathrm{C}$ ). The final bed contained only 0.4 percent fluoride, which indicated that about 97 percent of the uranyl fluoride was converted to $\mathrm{U}_{3} \mathrm{O}_{8}$. Considerably less reaction occurred in the continuous operation with hexafluoride feed. Products were multicolored, and analyses indicated that some uranium tetrafluoride was present. A more dense product, as determined by measurements of bulk density, was obtained with the hydrogen-steam mixtures than with steam alone. A somewhat higher nickel content ( $32 \mathrm{ppm}$ ) was noted in these products as compared with $5 \mathrm{ppm}$ in the uranyl fluoride prepared at $200 \mathrm{C}$.

Inspection of the reactor after $14.5 \mathrm{hr}$ of cumulative run time showed that the internal surface of both the reactor and the one-inch line which connects the reactor and the filter section were uncoated. It thus appears that hydrolysis at $500 \mathrm{C}$ achieves the primary aim of reducing the problem of solids deposition. No difficulty would be anticipated in the conversion of the solid products of the high-temperature hydrolysis step to uranium dioxide.

Of some consequence is the fact that appreciably greater quantities of fines were produced during these experiments than in the hydrolysis runs at $230 \mathrm{C}$. In one case as much as 50 percent of the hexafluoride feed formed fines. An increased concentration of fines in the bed was observed, although no interference with fluidization occurred. Most of the fines were carried over to the filter section. Further study would 
be expected to show conditions which would reduce fines formation to the levels encountered in the hydrolysis runs at $230 \mathrm{C}$, a parallel being the work cited immediately below.

\section{b. Particle Size Effects during Hydrolysis}

A study of the effect of initial average particle size of the bed on overall particle size behavior during hydrolysis was made in the 3-in.-diameter column with the integral filter vessel (see Fig. 2). Early scouting tests indicated that excessive amounts of low-density fines were formed when the average particle size of the bed was below $200 \mu$. In these experiments, no seed particles were added. Filter fines, however, were returned to the bed by filter blowback. Particle size distributions of starting and final beds were compared by sieve analyses of duplicate samples. The runs ranged from $20 \mathrm{~min}$ to $1.5 \mathrm{hr}$ in length, and measured growth rates were compared with calculated estimates (see Appendix, page 37).

In Runs 61,61 A, 61 B, and 61 C (see Table 6), the average particle diameter of the final bed was close to calculated estimates. The calculated estimates of the growth rates were slightly lower (in most cases) than experimental values, perhaps as a result of some fines holdup in the column. Starting bed average particle diameters ranged from 194 to $225 \mu$. Different size distributions, but with similar average particle diameters, were used in Runs $61 \mathrm{~B}$ and $61 \mathrm{C}$. This change in particle size distribution showed no effect on the growth rate.

Table 6

PARTICLE SIZE EFFECTS DURING HYDROLYSIS NOTED AS A FUNCTION OF

$$
\text { STARTING BED PARTICLE SIZE }
$$

$\begin{array}{ll}\text { Equipment: } & 3-\mathrm{in} \text { - -diameter Monel column } \\ \text { UF6 Rate: } & 100 \mathrm{~g} / \mathrm{min} \\ \text { Steam Superficial Velocity: } & 0.75 \mathrm{ft} / \mathrm{sec} \\ \text { Steam Excess: } & 225 \mathrm{percent} \\ \text { Starting Bed: } & 7 \text { to } 8 \mathrm{~kg} \text { of uranyl fluoride } \\ \text { Bed Temperature: } & 200 \text { to } 230 \mathrm{C}\end{array}$

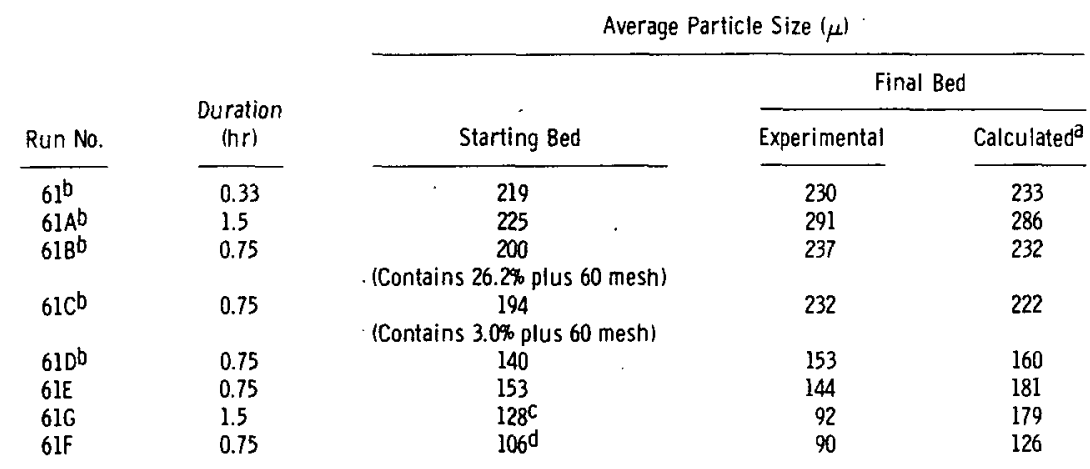

a See method of calculating average diameter of the bed particles in the Appendix, page 37. bNo product take-off.

CAverage bed particle diameter after $0.75 \mathrm{hr}$ was $133 \mu$; however, the -325 mesh fraction had increased from 0.1 to 2.3 percent.

dFinal bed of an early run which was terminated because of excessive fines formation. 
In Runs $61 \mathrm{E}$ through $61 \mathrm{G}$, a decrease in the average particle size was noted, thereby indicating that the rate of growth of the particles was reduced. In Run D, although some overall growth occurred, the $-200 \mathrm{mesh}$ fraction increased from 7.9 percent to 13.0 percent. When this bed was re charged in Run $E$, the rate of fines formation increased to such an extent that the average particle size of the bed decreased. This same effect was noted in Run $G$ in which a slight increase in the -325 mesh fraction from 0.1 to 2.3 percent occurred after $0.75 \mathrm{hr}$; by the end of this $1.5 \mathrm{hr}$ run, the minus 325 mesh fraction had increased to 10.6 percent. Run $F$ was made with the final bed from an earlier run which was interrupted after $6 \mathrm{hr}$ be cause of extensive fines formation; fines continued to build up. In a few instances, fines buildup was sufficient to cause bridging of the solids in the bed and to cause interference with fluidization of the bed. The results of these tests emphasize the need for good bed particle size control during continuous operation.

\section{B. Fluid-bed Reduction of Uranyl Fluoride to Uranium Dioxide}

The second step of the two-step fluid-bed process for preparing uranium dioxide from uranium hexafluoride involves the reduction of uranyl fluoride to the dioxide. The objectives of the development work on this step were to investigate the effects of operational variables and to attempt to establish conditions for preparing a low-fluoride dioxide powder. The scope of this investigation is summarized in Table 7, which lists the process variables and the ranges studied. These variables were studied in separate series of batch runs which were evaluated on the basis of the rate or extent

Table 7

SUMMARY OF RANGE OF OPERATING VARIABLES EVALUATED IN THE FLUID-BED REDUCTION OF URANY L FLUORIDE TO URANIUM DIOXIDE

$\frac{\text { Operating Variable }}{\text { Reactant Gas Composition }}$

Gas Velocity

Bed Temperature

Bed Depth

Bed Particle Size

Range
7 to 76 percent steam in hydrogen;
100 percent hydrogen; 100 percent steam;
50 percent hydrogen and 50 percent
nitrogen
0.2 to $2.0 \mathrm{ft} / \mathrm{sec} \mathrm{(minimum} \mathrm{fluidizing}$
velocity: $\sim 0.25 \mathrm{ft} / \mathrm{sec}$ )
550,600, and $650 \mathrm{C}$
5 to 23 in. $(1.7$ to $9 \mathrm{~kg}$ of uranyl fluoride)
Average particle diameters of 335,380,
and $630 \mu$.


of fluoride removal for a given reaction period. Results and discussion of the se experiments and final process conditions are presented below. A description of the equipment can be found in Section III, page 9.

1. Results and Discussion of Batch Fluid-bed Reduction Runs

\section{a. Effect of Gas Composition}

In the studies on the effect of gas composition on the reduction of uranyl fluoride to uranium dioxide, hydrogen-steam mixtures containing from 7 to 76 percent steam, hydrogen alone, or hydrogen diluted with nitrogen were used. A single experiment with 100 percent steam was also made. Runs were made in the temperature range from 550 to $650 \mathrm{C}$ with bed charges of 1.7 to $9 \mathrm{~kg}$ of uranyl fluoride ( 5 to $23 \mathrm{in}$. static bed height).

\section{Hydrogen-Steam Runs}

Results of the hydrogen-steam runs are summarized in Table 8 and shown graphically in Fig. 7. For comparison, a run made with a 50-50 mixture of hydrogen and nitrogen (see Table 9 for other hydrogen runs) and a run made with a 33-67 mixture of steam and nitrogen are included. The addition of steam to the hydrogen stream was found to

\section{Table 8}

RESULTS OF THE CONVERSION OF URANYL FLUORIDE TO URANIUM DIOXIDE WITH HYDROGEN-STEAM MIXTURES

Equipment: 3 -in.-diameter Monel column

Bed Temperature: $650 \mathrm{C}$

Starting Bed: $\quad 3 \mathrm{~kg}(-20+40$ mesh size $)$ uranyl fluoride

Gas Inlet

Composition

(\%)

\begin{tabular}{|c|c|c|c|}
\hline & & & \\
\hline No. & $\mathrm{H}_{2}$ & $\mathrm{H}_{2} \mathrm{O}$ & $\mathrm{N}_{2}$ \\
\hline 12 & 50 & 0 & 50 \\
\hline 14 & 93 & 7 & 0 \\
\hline 16 & 88 & 12 & 0 \\
\hline 17 & 73 & 27 & 0 \\
\hline 15 & 54 & 46 & 0 \\
\hline 18 & 24 & 76 & 0 \\
\hline 10 & 0 & 33 & 67 \\
\hline
\end{tabular}

$\mathrm{U}^{+6}$ in

Superficial Final

Gas Velocity Bed

$(\mathrm{ft} / \mathrm{sec})$

3.0

1.8

1.9

1.9

2.0

1.9

1.7
$(\%)$

54.5

2.1

2.3

1.7

3.9

2.6

$-$
Weight Percent

Fluoride in Samples

\begin{tabular}{|c|c|c|c|}
\hline $30 \mathrm{~min}$ & $60 \mathrm{~min}$ & $120 \mathrm{~min}$ & $240 \mathrm{~min}$ \\
\hline - & 12.2 & 11.7 & 7.84 \\
\hline 6.82 & 2.46 & 0.10 & 0.09 \\
\hline 7.63 & 3.46 & 0.16 & 0.07 \\
\hline 6.20 & 2.00 & 0.09 & 0.03 \\
\hline 4.08 & 0.50 & 0.06 & 0.02 \\
\hline 6.20 & 2.86 & 0.15 & 0.03 \\
\hline- & 4.60 & 0.50 & - \\
\hline
\end{tabular}




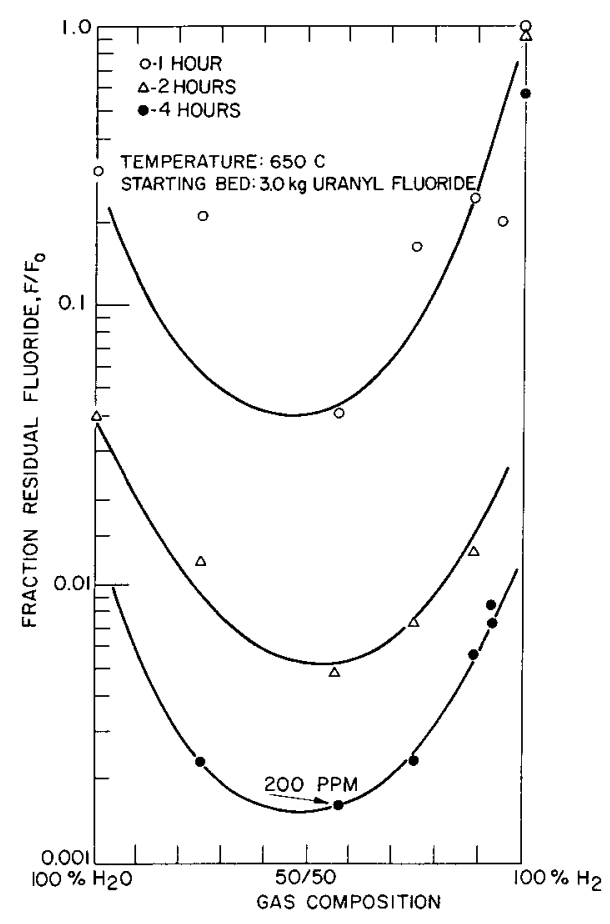

Figure 7

THE EFFECT OF GAS COMPOSITION ON THE REMOVAL OF FLUORIDE WITH RESPECT TO REACTION TIME

$108-4653$

Table 9

RESULTS OF REDUCTION OF URANYL FLUORIDE TO

URANIUM DIOXIDE WITH HYDROGEN

Equipment: 3-in.-diameter Monel column

\begin{tabular}{|c|c|c|c|c|c|c|}
\hline $\begin{array}{l}\text { Run } \\
\text { No. }\end{array}$ & $\begin{array}{l}\text { Bed } \\
\text { Temp } \\
\text { (C) }\end{array}$ & $\begin{array}{c}\text { Bed } \\
\text { Weight } \\
(\mathrm{kg})\end{array}$ & $\begin{array}{l}\text { Bed } \\
\text { Height } \\
\text { (in.) }\end{array}$ & $\begin{array}{c}\mathrm{H}_{2} \text { Rate } \\
(\mathrm{cfm}, 25 \mathrm{C} \\
1 \mathrm{~atm})\end{array}$ & $\begin{array}{l}\text { Time } \\
(\mathrm{min})\end{array}$ & $\begin{array}{l}\text { Residual } \\
\text { Fluoride } \\
\text { (w/o) }\end{array}$ \\
\hline 2 & 650 & 8 & 20 & 1.2 & 410 & 11.3 \\
\hline \multirow[t]{3}{*}{$12^{\mathrm{b}}$} & 650 & 3 & 8 & 1.3 & 60 & 12.2 \\
\hline & & & & & 240 & 7.8 \\
\hline & & & & & 360 & 1.1 \\
\hline 8 & 650 & 1.7 & 5 & 0.7 & 240 & 9.8 \\
\hline 1 & 600 & 8 & 20 & 1.3 & 360 & 11.3 \\
\hline 3 & 600 & 3 & 8 & 0.7 & 120 & 11.7 \\
\hline 4 & 550 & 3 & 8 & 0.8 & 300 & 11.8 \\
\hline
\end{tabular}

anitial fluoride content was 12.3 percent.

bA 50-50 mixture of hydrogen and nitrogen was used in this run only. Undiluted hydrogen was used in all other runs. 
enhance markedly the rate of removal of fluoride. With only seven percent steam in the hydrogen stream, the fluoride content of the bed was reduced from an initial value of 12.3 percent (theoretical fluoride content of uranyl fluoride) to 0.09 percent in $240 \mathrm{~min}$. In an equal time period, the best run with hydrogen (the one where a 50-50 hydrogen-nitrogen mixture was used) showed a final fluoride content of 7.8 percent. A plot of the data showed the optimum gas composition to be about a 50-50 mixture of steam and hydrogen. A residual fluoride content of $200 \mathrm{ppm}$ was achieved in $4 \mathrm{hr}$ with a mixture containing 46 percent steam (see Run 15, Table 8). In the run in which steam alone was used, Run 10 , the product was $\mathrm{U}_{3} \mathrm{O}_{8}$ rather than the dioxide. The residual fluoride content of this material was 0.5 weight percent.

The hexavalent uranium content of the product from the mixed-reactant runs ranged from 1.7 to 3.9 percent (see Table 8 ). These values are somewhat higher than expected in view of the high degree of reduction indicated by the low fluoride contents of the samples. However, this may be the result of partial oxidation of the dioxide product upon exposure to air immediately after processing. No further significant oxidation was noted after two additional months of exposure to air at room temperature.

\section{Hydrogen Runs}

Very slow removal of fluoride was achieved with the hydrogen-only runs (see Table 9) in comparison with the runs with mixed reactants. For beds of 3 and $8 \mathrm{~kg}$, the fluoride content was reduced from an initial value of 12.3 percent to only 11.3 percent after 410 min at $650 \mathrm{C}$. Similar results were achieved at lower temperatures. Increased removal of fluoride was noted when the bed size was reduced to $1.7 \mathrm{~kg}$ and when the hydrogen gas was diluted with nitrogen, i.e., when a 50-50 hydrogennitrogen mixture was used. Residual fluoride contents after 240 min were 9.8 percent when the bed size was reduced and 7.8 percent when the 50-50 mixture of hydrogen and nitrogen was used. With the diluted hydrogen, extension of the period to 360 min effected furthe $r$ removal of the fluoride and resulted in a residual fluoride content of 1.1 percent.

The poor results which were obtained in runs in which hydrogen alone was used may be attributed to the formation of a layer of uranium tetrafluoride, which inhibits the reduction of uranyl fluoride to uranium dioxide. The tetrafluoride is formed by the reaction of the dioxide with the hydrogen fluoride produced during reduction. The improved results obtained in the shallow-bed run and in the run made with the hydrogen-nitrogen are indirect evidence of this effect. The shallow bed provides less residence time in the bed for the gaseous hydrogen fluoride. With nitrogen dilution, the reduction reaction was slower and the partial pressure of hydrogen fluoride in the reaction off-gas was appreciably less, and hence the driving force for the secondary reaction would be reduced. 
In subsequent studies, the 50-50 steam-hydrogen mixture was used, since its use gave the best fluoride removals. Specific conditions such as bed size or particle size range are noted in the separate sections.

\section{b. Effect of Gas Velocity}

The effect of gas velocity was evaluated in terms of fluoride-removal rate while keeping the bed weight, initial particle size distribution, and bed temperature fixed at the following conditions: $3 \mathrm{~kg}$ of $-40+60$ mesh size uranyl fluoride (static bed height about 8 in.) and $650 \mathrm{C}$. The 50-50 steam-hydrogen mixture was used as the reactant stream. Results (see Table 10) showed that the rate of fluoride removal was more rapid when higher velocities were used. High-quality material (<250 ppm fluoride) was produced in less than $3 \mathrm{hr}$ at $2.0 \mathrm{ft} / \mathrm{sec}$, whereas more than $3 \mathrm{hr}$ were required to achieve the same fluoride removal when velocities of about $1.0 \mathrm{ft} / \mathrm{sec}$ were used. The single experiment (Run 28) at sub-fluidizing conditions produced material containing 350 ppm fluoride after $4 \mathrm{hr}$. Since higher velocities introduce greater amounts of reactants in a given interval, the improved conversion rate may be due to this rather than to velocity alone. It is also possible that mixing action or efficiency of gas-solid contact is improved at the higher velocities and also contributes to the higher conversion rates. A disadvantage in working with high

Table 10

THE EFFECT OF GAS VELOCITY ON THE CONVERSION OF URANYL FLUORIDE TO URANIUM DIOXIDE

$\begin{array}{ll}\text { Equipment: } & 3 \text {-in.-diameter Monel column } \\ \text { Temperature: } & 650 \mathrm{C} \\ \text { Starting Bed: } & 3 \mathrm{~kg} \text { of uranyl fluoride } \\ \text { Particle Size: } & -40+60 \text { mesh size } \\ \text { Gas Composition: } & 50-50 \text { hydrogen-steam }\end{array}$

\begin{tabular}{|c|c|c|c|c|c|c|}
\hline \multirow[b]{2}{*}{$\begin{array}{l}\text { Run } \\
\text { No. }\end{array}$} & \multirow{2}{*}{$\begin{array}{c}\text { Superficial } \\
\text { Velocity } \\
(\mathrm{ft} / \mathrm{sec})\end{array}$} & \multirow{2}{*}{$\begin{array}{l}\text { Hydrogen Feed } \\
\quad(\mathrm{x} \text { Stoich })\end{array}$} & \multicolumn{4}{|c|}{$\begin{array}{l}\text { Weight Percent } \\
\text { Fluoride in Sample }\end{array}$} \\
\hline & & & $60 \mathrm{~min}$ & $120 \mathrm{~min}$ & $180 \mathrm{~min}$ & $240 \mathrm{~min}$ \\
\hline 28 & $0.2^{\mathrm{a}}$ & 2.5 & - & - & - & 0.035 \\
\hline 33 & 0.6 & 7.6 & 3.1 & 0.086 & 0.025 & 0.010 \\
\hline 30 & 0.8 & 10.1 & 3.9 & 0.33 & 0.031 & 0.015 \\
\hline 21 & 1.3 & 16.5 & - & 0.26 & 0.028 & 0.015 \\
\hline 32 & 1.8 & 22.8 & 0.21 & 0.026 & 0.010 & 0.008 \\
\hline 31 & 2.0 & 25.3 & 0.18 & 0.033 & 0.010 & - \\
\hline
\end{tabular}

a Static-bed run; minimum fluidizing gas velocity $0.25 \mathrm{ft} / \mathrm{sec}$. 
gas rates is that large quantities of reactants are required, for example, about 25 times stoichiometric at $2 \mathrm{ft} / \mathrm{sec}$.

$$
\text { c. Effect of Temperature }
$$

The effect of temperature on the rate of fluoride removal was studied at temperatures ranging from 600 to $650 \mathrm{C}$. Beds containing $9 \mathrm{~kg}$ of uranyl fluoride in the size range of $-10+60$ mesh were used. Data summarized in Table 11 show higher operating temperatures result in more rapid conversion. Material containing $250 \mathrm{ppm}$ or less of residual fluoride was obtained in $4 \mathrm{hr}$ at $650 \mathrm{C}$ and in $7 \mathrm{hr}$ at $600 \mathrm{C}$.

Table 11

THE EFFECT OF TEMPERATURE ON THE CONVERSION OF URANYL FLUOR IDE TO URANIUM DIOXIDE

Equipment:

Starting Bed:

Superficial Gas Velocity:

Gas Composition:
3 -in.-diameter Monel column

$9 \mathrm{~kg}(-10+60$ mesh size $)$ of uranyl fluoride

1.3 to $1.6 \mathrm{ft} / \mathrm{sec}$

50-50 hydrogen-steam

Weight Percent Fluoride in Sample

\begin{tabular}{|c|c|c|c|c|c|c|}
\hline \multirow{2}{*}{$\begin{array}{l}\text { Run } \\
\text { No. }\end{array}$} & \multirow{2}{*}{$\begin{array}{c}\text { Temperature } \\
\text { (C) }\end{array}$} & \\
\hline & & $2 \mathrm{hr}$ & $4 \mathrm{hr}$ & $5 \mathrm{hr}$ & $6 \mathrm{hr}$ & $7 \mathrm{hr}$ \\
\hline 34 & 650 & 0.10 & 0.018 & 0.008 & 0.007 & - \\
\hline 36 & 625 & 1.40 & 0.070 & 0.031 & 0.026 & 0.017 \\
\hline 35 & 600 & 1.90 & 0.069 & 0.039 & 0.029 & 0.025 \\
\hline
\end{tabular}

d. Effect of Bed Depth

The effect of bed depth on the rate of conversion of uranyl fluoride to uranium dioxide was investigated with the use of initial static bed heights of 8 to 23 in. Bed weights were $3,6,7.5$, and $9 \mathrm{~kg}$. All of the experiments were conducted at $650 \mathrm{C}$. Analytical results of samples taken after 2, 4, 5, and $6 \mathrm{hr}$ are summarized in Table 12. All of the beds were reduced to low levels of fluoride $(<250 \mathrm{ppm})$ within $4-\mathrm{hr}$ periods, with the shallowest bed showing the lowest fluoride content, namely $100 \mathrm{ppm}$, as compared with about $200 \mathrm{ppm}$ in the other runs. Again, in these studies as in the studies on the effect of gas velocity, it is possible that the results obtained in these experiments depended not only on bed depth but also on reactant excess. 
Table 12

RESULTS OF THE BED-DEPTH STUDY ON THE CONVERSION OF URANYL FLUORIDE TO URANIUM DIOXIDE

$\begin{array}{ll}\text { Equipment: } & 3 \text {-in.-diameter Monel column } \\ \text { Temperature: } & 650 \mathrm{C} \\ \text { Superficial Gas Velocity: } & 1.5 \mathrm{ft} / \mathrm{sec} \\ \text { Gas Composition: } & 50-50 \mathrm{hydrogen}-\mathrm{steam} \\ \text { Starting Bed: } & 3 \text { to } 9 \mathrm{~kg} \text { of uranyl fluoride, } \\ & 50 \text { percent }-20+40 \text { mesh, } \\ & 50 \text { percent }-40+60 \text { mesh }\end{array}$

Bed Weight Percent Fluoride in Sample

Ru
No
Depth

Run Weight (in.)

$4 \mathrm{hr}$

$5 \mathrm{hr}$

$6 \mathrm{hr}$

34

37

38

39

\section{9}

15

8
0.10

0.10

0.05

0.108
0.018

0.022

0.019

0.010
0.008

0.016

0.010
0.007

0.011

0.014

\section{e. Effect of Initial Particle Size}

Three-kilogram beds of uranyl fluoride of different average particle sizes were reacted at $650 \mathrm{C}$ to investigate the effect of initial particle size. The average particle diameters were 335,380 , and $630 \mu$ (in the range -20 to $+60 \mathrm{mesh}$ ), calculated from the formula for the average volume-surface diameter $D_{\mathrm{vs}}$ :

$$
D_{\mathrm{vs}}=\frac{\overline{\mathrm{w}}}{\sum \frac{\mathrm{w}_{\mathrm{i}}}{\mathrm{d}_{\mathrm{i}}}},
$$

where

$$
\begin{aligned}
\vec{w} & =\text { sum of the weight percents of solids retained on each sieve } \\
w_{i} & =\text { weight percent of solids retained on each sieve } \\
d_{i} & =\text { mean diameter of the mesh sizes of two adjacent sieves. }
\end{aligned}
$$

No marked effect of particle size was noted, as shown in the summary of data in Table 13. However, the fluoride content of the smaller-sized particles fell below $200 \mathrm{ppm}$ within $3 \mathrm{hr}$, whereas the coarse material attained this value after $4 \mathrm{hr}$. The apparent inconsistency of data after the second hour may be due to sampling or analytical error. 
Table 13

THE EFFECT OF FEED PARTICLE SIZE ON THE CONVERSION OF URANY L FLUORIDE TO URANIUM DIOXIDE

Equipment:

Temperature:

Starting Bed:

Gas Composition: 3-in.-diameter Monel column

$650 \mathrm{C}$

$3 \mathrm{~kg}$ of uranyl fluoride

50-50 hydrogen-steam

\begin{tabular}{|c|c|c|c|c|c|c|}
\hline \multirow{2}{*}{$\begin{array}{l}\text { Run } \\
\text { No. }\end{array}$} & \multirow{2}{*}{$\begin{array}{c}\text { Superficial } \\
\text { Velocity } \\
(\mathrm{ft} / \mathrm{sec})\end{array}$} & \multirow{2}{*}{$\begin{array}{l}\text { Average } \\
\text { Particle } \\
\text { Diameter } \\
(\mu)\end{array}$} & \multicolumn{4}{|c|}{ Weight Percent Fluoride in Sample } \\
\hline & & & $60 \mathrm{~min}$ & $120 \mathrm{~min}$ & $180 \mathrm{~min}$ & $240 \mathrm{~min}$ \\
\hline 15 & 2.0 & $\begin{array}{c}630 \\
\text { (20 to } 40 \mathrm{mesh})\end{array}$ & 0.50 & 0.060 & - & 0.020 \\
\hline 39 & 1.5 & $380^{\mathrm{a}}$ & 0.48 & 0.108 & 0.014 & 0.010 \\
\hline 32 & 1.8 & $\begin{array}{c}335 \\
\text { (40 to } 60 \text { mesh) }\end{array}$ & 0.21 & 0.030 & 0.010 & 0.008 \\
\hline
\end{tabular}

a Average volume-surface particle diameter $D_{v s}$ (see page 28 for definition).

2. Powder Properties

Appreciable breakup of the individual particles occurred during the reduction step, as shown in the following typical sieve analyses:

Weight Fraction Retained on Given Sieve Size

\begin{tabular}{cccccccc}
\hline+20 & +40 & +60 & +100 & +200 & +325 & -325 \\
\hline 0.01 & 0.55 & 0.41 & 0.03 & 0 & 0 & 0 \\
0.01 & 0.14 & 0.30 & 0.28 & 0.17 & 0.08 & 0.02 \\
- & - & 0.35 & 0.17 & 0.12 & 0.22 & 0.14
\end{tabular}

Microscopic examination of these samples showed many hull-shaped fragments (see Fig. 8) and the presence of voids (see Fig. 9). More severe breakup appeared to occur at the lower temperature (36 percent $-200 \mathrm{mesh}$ at $550 \mathrm{C}$ as compared with 10 percent at $650 \mathrm{C}$ ). A reason for this is suggested by the work of Clayton and Aronson, (22) who found that strains resulting from phase transformations were less easily annealed at lower temperatures. The relationship between the degree of conversion and particle breakup was not established during the course of this work, but separate attrition tests with nitrogen at elevated temperatures and similar 
process velocities resulted in negligible particle breakup; therefore, the particle breakup was definitely associated with the reduction reaction. Overall results showed an average decrease in mean particle size of 40 to $50 \mu$ per hour of reduction time. It may be desirable, therefore, to minimize the duration of the reduction period.

\section{Figure 8}

URANIUM DIOXIDE PRODUCT SHOWING HULL-SHAPED FRAGMENTS

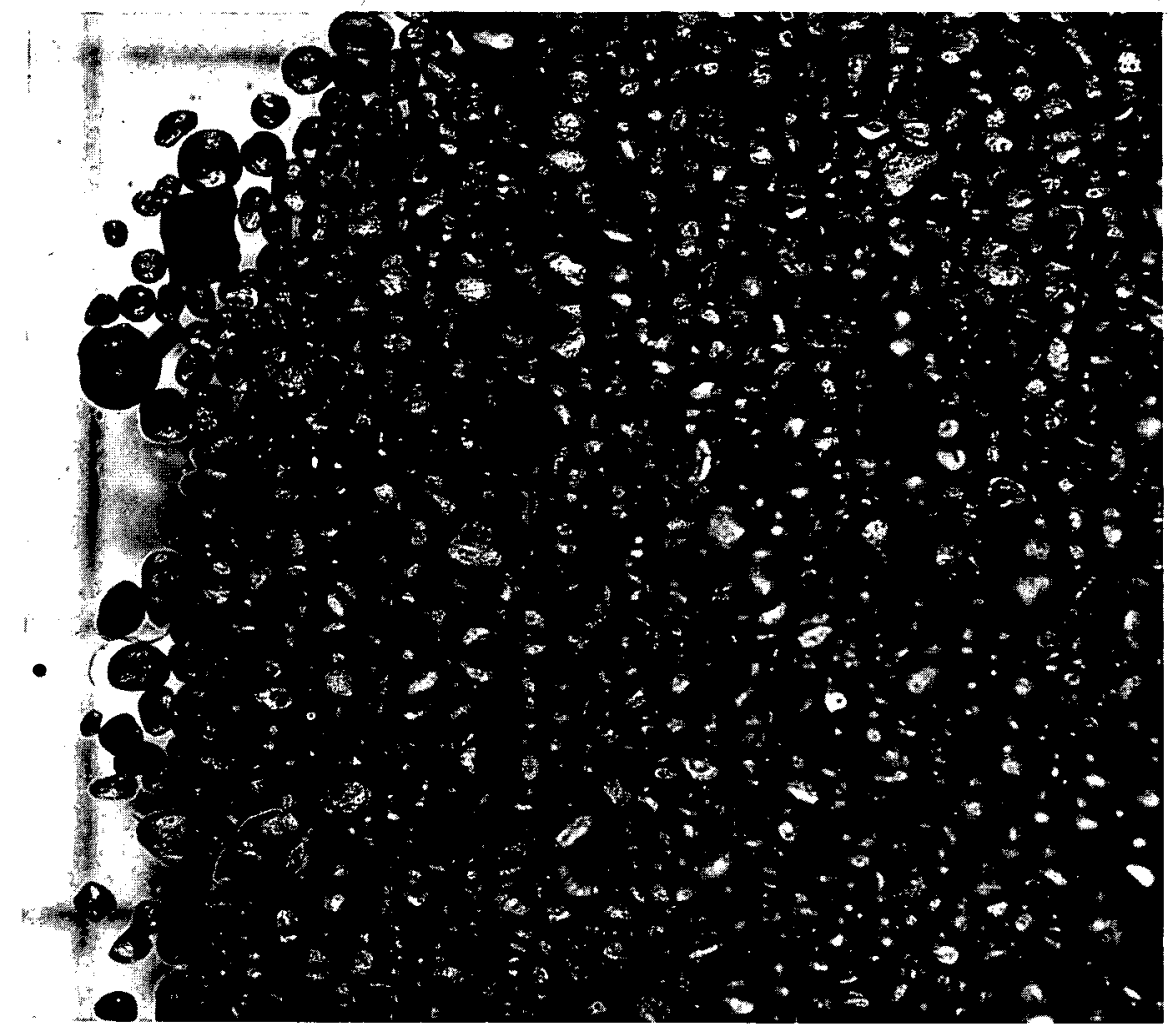

(Magnification - 24X)

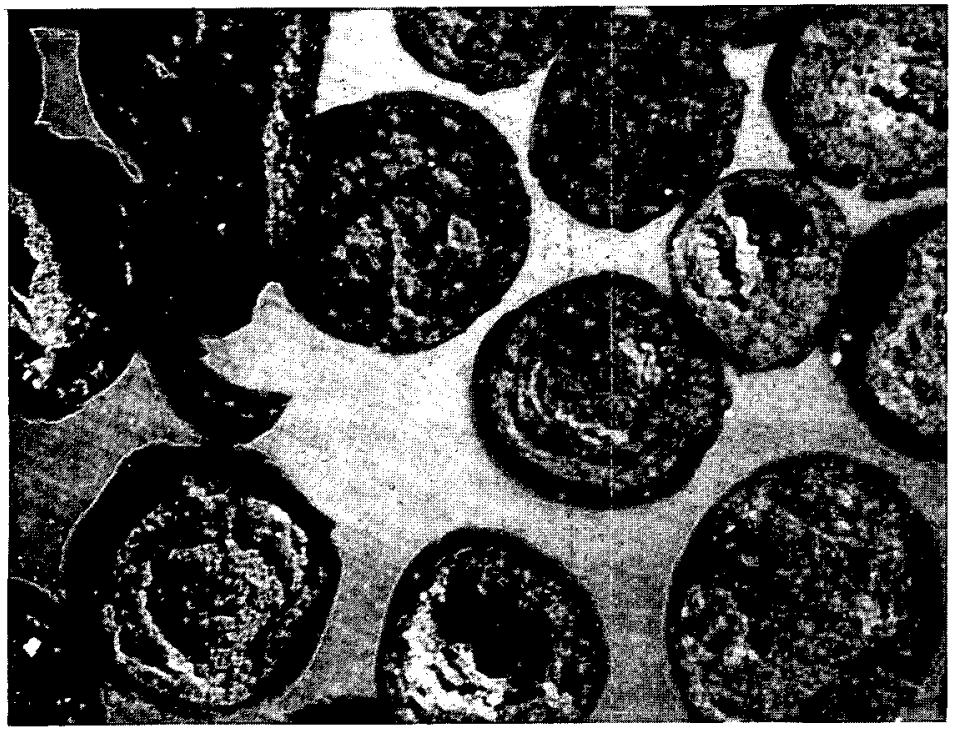

Figure 9

URANIUM DIOXIDE SAMPLE SHOWING PARTICLE VOIDS

(Magnification - 40X) 
The presence of fine material, even to the extent of 35 percent as in the run made at $550 \mathrm{C}$ (see Run 4, Table 9), did not seem to be of serious consequence, since no difficulties were experienced in maintaining fluidization. Since the uranium dioxide product is to be ground to -200 or -325 mesh for pellet fabrication, the presence of this quantity of fines may not be a disadvantage.

The tap bulk density of the dioxide product was found to vary from 4.2 to $4.8 \mathrm{~g} / \mathrm{cc}$. The densities of individual particles were determined by two different methods. The average values obtained were $9.7 \mathrm{~g} / \mathrm{ml}$ in xylene and $6.2 \mathrm{~g} / \mathrm{ml}$ in mercury. (20) The determinations made with mer cury give a measure of the overall porosity of the particle, whereas the measurements with xylene indicate the degree of open pore structure. For reference, the theoretical density of the uranium dioxide crystal is $10.96 \mathrm{~g} / \mathrm{cc}$. Measurement of surface area by the adsorption of nitrogen gas on the surface of the particles in the $-60+100$ mesh fraction gave a value of $0.82 \mathrm{sq} \mathrm{m} / \mathrm{g}$. Areas higher by an order of magnitude have been reported for uranium dioxide, the exact values being dependent on the mode of preparation.

Contaminants in the dioxide powder product other than fluoride were found to be primarily the constituents of Monel metal, which was used as a structural material in both steps of this process. Chemical analysis of the starting material, uranyl fluoride produced at temperatures near $200 \mathrm{C}$, showed the presence of about $5 \mathrm{ppm}$ nickel. The nickel content of the dioxide product bed was considerably higher, as shown in the analysis below:

\begin{tabular}{ccccc}
$\begin{array}{c}\text { Reduction } \\
\text { Temperature } \\
\text { (C) }\end{array}$ & $\begin{array}{c}\text { Run } \\
\text { Duration } \\
(\mathrm{hr})\end{array}$ & & \multicolumn{3}{c}{$\begin{array}{c}\text { Uranium Dioxide } \\
\text { Product (ppm) }\end{array}$} \\
\cline { 4 - 6 } 650 & 6 & & $\mathrm{Ni}$ & Cu \\
600 & 8 & 70 & 160 & 40 \\
& & 200 & 100 & 30
\end{tabular}

An intermediate sample taken from the run made at $650 \mathrm{C}$ (Run 34) contained about 70 ppm nickel after $2 \mathrm{hr}$ as compared with $160 \mathrm{ppm}$ after $6 \mathrm{hr}$, thus indicating that product contamination is time dependent. On the basis of these results, it may be advisable to operate at the lower temperature or attempt to optimize the time-temperature cycle. It may also be possible to reduce the amounts of contaminants by the use of reactor construction material, such as Inconel, which might prove to be more resistant to corrosion. 
C. Results of Sintering Tests on Dioxide Produced by the Fluid-bed Process

Samples of dioxide product prepared by the separate reaction procedure and by a simultaneous reaction procedure $(23,24)$ were tested for sinterability. Separate tests were carried out by J. Handwerk of the Argonne National Laboratory Ceramics Group and by Mallinckrodt Nuclear Corporation, St. Louis, Missouri. Table 14 summarizes comparative experiments carried out at Argonne National Laboratory on batches of powder prepared by the two process routes. The powders were ground by ball milling to -325 mesh and sintered at $1700 \mathrm{C}$ in dry hydrogen. No binder was used. A slightly higher density was obtained with the oxide prepared by the simultaneous reaction process as compared with the oxide prepared by the separate reaction process: 96.7 percent of theoretical as compared with 94.7 percent of theoretical.

Table 14

\section{RESULTS OF PELLET FABRICATION EXPERIMENTS ${ }^{a}$ ON URANIUM DIOXIDE PREPARED BY FLUID-BED CONVERSION OF URANIUM HEXAFLUORIDE}

\begin{tabular}{|c|c|c|c|c|c|}
\hline \multirow{2}{*}{\multicolumn{6}{|c|}{-325 mesh uranium dioxide }} \\
\hline & & & & & \\
\hline \multirow{2}{*}{\multicolumn{2}{|c|}{$\begin{array}{l}\text { Pellet Size: } \\
\text { Pelleting Pressures: }\end{array}$}} & \multicolumn{4}{|c|}{$\frac{1}{2}-$ in. diameter $\times \frac{1}{2}-i n \cdot$ high } \\
\hline & & \multicolumn{4}{|c|}{$\begin{array}{l}8000-p s i \text { pre-press followed by a } 25 \text {-tsi } \\
\text { isostatic press }\end{array}$} \\
\hline Sintering $\operatorname{Prc}$ & dure: & \multicolumn{4}{|c|}{$\begin{array}{l}\text { Heat to } 1200 \mathrm{C} \text { overnight; increase temperature } \\
\text { rapidly to } 1700 \mathrm{C} \text { and hold for } 2 \mathrm{hr} \text {; turn off } \\
\text { heat and cool overnight. }\end{array}$} \\
\hline \multirow[b]{3}{*}{ Run No. } & \multirow{2}{*}{\multicolumn{3}{|c|}{$\begin{array}{l}\text { Chemical Analysis } \\
\text { before Sintering } \\
\qquad(\mathrm{w} / \mathrm{o})\end{array}$}} & \multirow{3}{*}{$\begin{array}{l}\text { Surface Area by } \\
\text { Methylene Blue } \\
\text { Adsorption } \\
\quad(\text { sq } \mathrm{m} / \mathrm{g})\end{array}$} & \multirow{3}{*}{$\begin{array}{l}\text { Sintered } \\
\text { Pellet Density } \\
\text { (Percent } \\
\text { Theoretical) }\end{array}$} \\
\hline & & & & & \\
\hline & $\mathrm{F}$ & $\mathrm{U}^{+4}$ & $\mathrm{U}^{+6}$ & & \\
\hline 46 & 0.007 & 84.7 & 3.1 & 2.9 & 94.1 to 94.7 \\
\hline \multicolumn{6}{|l|}{$\begin{array}{l}\text { two-step } \\
\text { procedure) }\end{array}$} \\
\hline $\begin{array}{l}\quad 54 \\
\text { imultaneous } \\
\text { eaction } \\
\text { rocedure) }\end{array}$ & 0.054 & 86.8 & 1.8 & 3.4 & 96.6 to 96.9 \\
\hline
\end{tabular}

a Work done by the Argonne National Laboratory Ceramics Group under the direction of $\mathrm{J}$. Handwerk. 
The pelleting tests made by Mallinckrodt Nuclear Corporation (MCW Nuclear) utilized only the powder produced by the simultaneous reaction procedure. This powder contained $130 \mathrm{ppm}$ fluoride and 1.7 percent hexa valent uranium. A measurement of surface area (by nitrogen adsorption) of a $-60+100$ mesh fraction of this material gave a value of $1.94 \mathrm{sq} \mathrm{m} / \mathrm{g}$. A variety of treatments were given to portions of the powder (see Table 15). One portion was ball milled to -325 mesh and then divided into three parts which were treated as follows: one part was tested as is; the second part was wet ball milled for $5 \mathrm{hr}$; and the third part was put through two oxidation-reduction cycles, each consisting of a one-hour oxidation and a $4-\mathrm{hr}$ reduction at $650 \mathrm{C}$. The original coarse material, in the size range $-40+200$ mesh, was sintered both as discrete particles and in pellet form.

Table 15

SUMMARY OF SINTERING TESTS ${ }^{\mathrm{a}}$ PER FORMED ON URANIUM DIOXIDE PREPARED BY SIMULTANEOUS REACTION OF URANIUM HEXAFLUORIDE WITH STEAM AND HYDROGEN

Material: $\mathrm{UO}_{2}$ from Run $37 \mathrm{~A}$ ground to -325 mesh except for material A; fluoride content $130 \mathrm{ppm}$

Treatment of Material: A: As received (40 to $200 \mathrm{mesh}$ ) $\mathrm{B}-1$ : Used as prepared (-325 mesh)

$\mathrm{B}-2$ : Wet ball milling for $5 \mathrm{hr}$ B-3: Oxidized ( $1 \mathrm{hr}$ ) and reduced $(4 \mathrm{hr})$ at $650 \mathrm{C} ; 2$ cycles

Pelleting Pressures: 50,70, and 90 tsi

Sintering Conditions: Presintered at $900 \mathrm{C}$. Sintered for $8 \mathrm{hr}$ at $1650 \mathrm{C}$, plus heatup and cooldown time

\begin{tabular}{|c|c|c|c|}
\hline Treatment & $\begin{array}{l}\text { Density of } \\
\text { Unsintered } \\
\text { Pellet } \\
(\mathrm{g} / \mathrm{cc}) \\
\end{array}$ & $\begin{array}{c}\text { Sintered Density } \\
\text { as Percent of } \\
\text { Theoretical }\end{array}$ & Remarks \\
\hline A & - & - & Pellets found cracked \\
\hline$A^{b}$ & - & 93 & $\begin{array}{l}\text { Sintered as "shot" in this } \\
\text { test only }\end{array}$ \\
\hline$B-1$ & 7.4 to 7.9 & $\sim 95$ & Appreciable voids present ${ }^{C}$ \\
\hline$B-2$ & 7.34 to 7.86 & 93.5 to 96 & $\begin{array}{l}\text { Fewer voids at higher } \\
\text { pressures }\end{array}$ \\
\hline$B-3$ & 6.87 to 7.45 & 96.5 to 97.5 & Very few voids noticed \\
\hline
\end{tabular}

a Tests made by Mallinckrodt Nuclear Corporation.

$\mathrm{b}_{\mathrm{A}}$ lower (unspecified) sintering temperature was used in this test.

cPossibly due to excessive use of wax. 
Pellets from each of the -325 mesh samples gave sintered densities of about 95 percent of theoretical and showed little distortion. Even with these relatively high densities, a number of voids were observed in the pellets prepared from as-received -325 mesh powder. These voids were attributed in part to an excessive use of wax. Few voids were observed in the pellets from oxidized-reduced material. In general, fewer voids were observed in pellets made from material that had been pressed at higher pressures ( 90 tsi as compared with 50 and 70 tsi). Pellets prepared from the as-received $-40+200$ mesh powder were found to be cracked.

\section{CONCLUSION}

A direct two-step fluid-bed process for the production of uranium dioxide from uranium hexafluoride has been developed. Continuous reaction of hexafluoride with steam to produce uranyl fluoride followed by reaction of this intermediate solid with mixtures of steam and hydrogen produces a low-fluoride ( $<250 \mathrm{ppm}$ residual fluoride), sinterable uranium dioxide. The process offers equipment simplicity, high productivity, and the inherent advantages obtained from the use of fluidized beds, such as good heat transfer characteristics, mobility of solids, and product uniformity. 


\section{BIBLIOGRAPHY}

1. Murray, J. P., et al., Economics of Unirradiated Processing Phases of Uranium Fuel Cycles, Second United Nations International Conference on Peaceful Uses of Atomic Energy, Geneva, Switzerland, 13 , 439 (1958).

2. Knudsen, I. E., Levitz, N. M.., and Lawroski, S., Preliminary Report on Conversion of Uranium Hexafluoride to Uranium Dioxide in a One-step Fluid-bed Process, ANL-6023 (Aug 1959).

3. Glassner, Alvin, The Thermochemical Properties of the Oxides, Fluorides and Chlorides to $2500 \mathrm{~K}$, AN L-5750 (1957).

4. Popov, M. M., Kostylev, F. A., and Karpova, T. A., Heat of Formation of Uranyl Fluoride and Heat of Reaction of Uranium Hexafluoride and Tetrafluoride with Water, IGRL-T/CA-56, trans. by E. G. Peters from Zhur. Neorgan. Khim 2 , 9-12 (1957).

5. Katz, J.. J., and Rabinowitch, E., NNES, VIII-5, The Chemistry of Uranium, McGraw-Hill Publishing Co., New York (1951), p. 440.

6. Process Developments in the Manufacture of Uranium Hexafluoride, July 1957 - June 1959, K-1437 (July 14, 1960), p. 31.

7. Reese, S. L., et al., Summary Technical Report for the Period July 1, 1956 to September 30,1956, NLCO-650 (Oct 15, 1956), p. 131 .

8. Smiley, S. H., and Brater, D. C., Progress in Nuclear Energy, Series III Process Chemistry, Vol. 2, Pergamon Press, New York (1958), p. 177.

9. Katz, J.. J., and Rabinowitch, E., op. cit., p. 441.

10. Kuhlman, C. W., Reduction of Uranyl Fluoride with Hydrogen, MCW-175 (March 14, 1949).

11. Ferris, L. M., and Gardner, R. P., Recycle of $\mathrm{UO}_{2} \mathrm{~F}_{2}$ in the Fluorox Process: Reaction of $\mathrm{UO}_{2} \mathrm{~F}_{2}$ with Hydrogen, ORNL-2690 (July 9, 1959).

12. Katz, J.J.., and Rabinowitch, E., op. cit., p. 572.

13. Smiley, S. H., Oak Ridge Gaseous Diffusion Plant, June 24, 1960 (unpublished).

14. Ferris, L. M., and Gabbard, E. F., Kinetics of the Thermal Decomposition of Uranyl Fluoride, 1. Preliminary Results, ORNL-2401 (March 5, 1958). 
15. Notz, K. J., and Manser, W. C., Summary Technical Report for the Period July 1, 1956 to September 30, 1956, NLCO-650 (Oct 15, 1956), p. 66.

16. Bard, R. J., The Activation of Low-reactivity Uranium Dioxide Particles, LA-1952(Oct 1955).

17. Warf, J. C., Cline, W. D., and Tevebaugh, R. D., Pyrohydrolysis in the Determination of Fluoride and Other Halides, Anal. Chem. 26, 342-6 (1954).

18. Corder, J. L., Kirby, A. M., and Todd, J. E., Process Development Quarterly Report, Part II, NYO-1360 (Jan. 15, 1954), p. 55.

19. Browning, M F., Secrest, V. M., and Blocher, Jr., J. M., Progress Relating to Civilian Applications during September, 1961, BMI-1546 (Del.) (Oct 1, 1961), p. L-6.

20. Beirne, T., and Hutcheon, J. M., The Shape of Ground Petroleum Coke Particles, Brit. J. Appl. Phys., Sup. III, London, 76-80 (1954).

21. Katz, J. J., and Rabinowitch, E., op. cit., p. 569.

22. Clayton, J. C., and Aronson, Seymour, Some Preparative Methods and Physical Characteristics of Uranium Dioxide Powders, J. Chem. Eng. Data, 6, No. 1, 50 (1961).

23. Knudsen, I. E., Levitz, N. M., Finley, R., and Jones, M., Chemical Engineering Division Summary Report, October, November, December, 1959, ANL-6101 (Feb 1960), p. 125.

24. Knudsen, I. E., Levitz, N. M., Jones, M., and Kincinas, J., Chemical Engineering Division Summary Report, January, February, March, 1960, ANL-6145 (1960), p. 125.

25. Knudsen, I E., Levitz, N. M., and Jones, M., Chemical Engineering Division Summary Report, July, August, September, 1962, ANL-6596.

26. Brooks, L. H., Garner, E. V., and Whitehead, E., Chemical and X-ray Crystallographic Studies on Uranyl Fluoride, IGR-TN/CA-277 (Feb 9, 1960). 


\section{APPENDIX}

A. Fluid-bed Studies on the Preparation of Dense Uranium Dioxide Particles in a Single-step Operation

Uranium dioxide powder intended for use as a nuclear fuel is currently being formed into pellets via an expensive pelleting and sintering procedure. The pellets thus obtained are loaded into fuel tubes for use in reactors. A less expensive fabrication technique for such fuel tubes involves the use of uranium dioxide in powder form and employs vibratory compaction or swaging for final densification. Until now, dense uranium dioxide powder for use in these fuel-development studies has been obtained only by the grinding and sizing of fused material. The possibility of producing a dense form of powder directly in a fluid bed by the simultaneous reaction of steam and hydrogen with uranium hexafluoride is being investigated.

Experimental work is being conducted in the 3-in.-diameter column with the separate filter vessel (see Fig. 1). Starting beds of $6 \mathrm{~kg}$ of uranium dioxide were used. The size range of material in the bed was $-20+140$ mesh. The run procedure involves alternate periods of hexafluoride feed time followed by a residual fluoride cleanup period during which only steam and hydrogen are fed. In some runs, the steam rate during the cleanup period was increased over the rate used during the hexafluoride feed period in order to achieve the desired fluoride removal. The hexafluoride feed ontime period ranged from $20 \mathrm{~min}$ to one hour. The fluoride cleanup period was generally 30 min long. Product was removed semicontinuously (that is, after each cleanup period) so that the bed weight was maintained approximately constant. The final bed of one run was used as the starting bed of the next run. A sidestream of "seed" particles was added to the bed in order to maintain a uniform average particle size, that is, the addition of "seed" particles counterbalanced the growth of the bed particles which occurred as a consequence of the deposition of the solid products of the reaction on the surface of the particles. Hexafluoride feed rate ranged from 10 to $28 \mathrm{~g} / \mathrm{min}$, and the steam rate from 0.1 to 12.6 times the stoichiometric requirement.* The hydrogen rate was kept relatively high (10 to 20 times the stoichiometric requirement).

Particles with densities ranging from 8.5 to $9.5 \mathrm{~g} / \mathrm{cc}$ were produced at temperatures of $650 \mathrm{C}$ as determined by mercury-displacement measurements. A higher temperature, $700 \mathrm{C}$, resulted in particles with densities of 9.7 to $9.8 \mathrm{~g} / \mathrm{cc}$ (about 89 percent of theoretical). The higher densities were obtained in runs where the steam excess was in the range from 0.75 to 1.4 times the stoichiometric requirement. Material of lower density was produced in runs in which a small amount of steam (down to zero concentration) or a large amount of steam was employed. Density measurements by xylene displacement on material of 75 to 85 percent theoretical density gave values of 10.5 to $10.7 \mathrm{~g} / \mathrm{cc}$.

* Based on the reaction $\mathrm{UF}_{6}+2 \mathrm{H}_{2} \mathrm{O}+\mathrm{H}_{2} \rightarrow \mathrm{UO}_{2}+6 \mathrm{HF}$. 
Residual fluoride contents were held to 200 to $300 \mathrm{ppm}$ in most runs. The nickel content of the product ranged from 17 to $30 \mathrm{ppm}$, thereby indicating that the corrosion rates in the reactor were low. Fines carryover to the filter vessel averaged about 9 percent by weight of the hexafluoride feed input, although in some runs the carryover was as low as 2 percent.

\section{Characterization of the Dioxide Product}

In order to characterize the dioxide produced in these studies, pore size distributions* were determined for three representative samples, after which the samples were sintered in hydrogen. The smooth, spheroidal appearance of the particles, which are typical of the material produced in the fluid bed, is shown in Fig. 10. In Fig. 11, the cross sections of particles show the uniform manner in which the layers were deposited. A relatively high-magnification (533X) photomicrograph of a cross-sectioned particle (Fig. 12) shows the fine-grained structure of the particle. Pore size measurements of samples with densities of $8.5,9.3$, and $9.75 \mathrm{~g} / \mathrm{cc}$ indicated that most of the pores were less than $0.4 \mu$ in diameter and that a significant number were smaller than $0.06 \mu$ in diameter.

Figure 10

DENSE URANIUM DIOXIDE PARTICLES AS PRODUCED IN THE FLUID-BED REACTOR

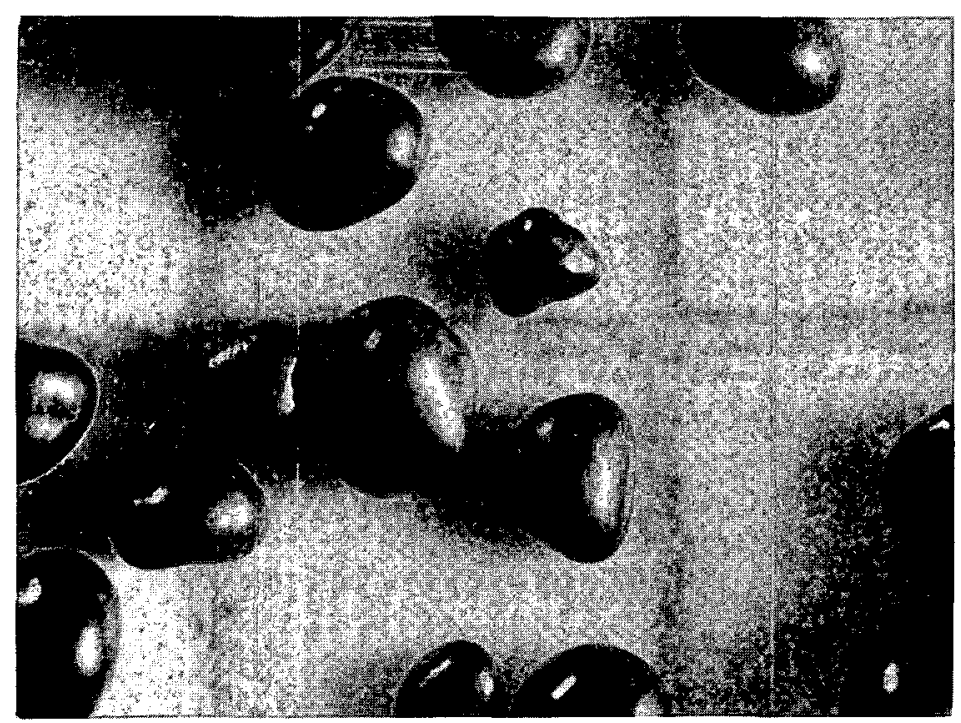

$108-5661$

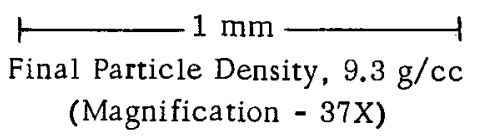

* Pore size distribution was measured by means of a porosimeter by Armour Research Foundation, Chicago, Illinois. 
Figure 11

CROSS SECTION OF DENSE URANIUM DIOXIDE PARTICLES SHOWING LAYER

DEPOSITION

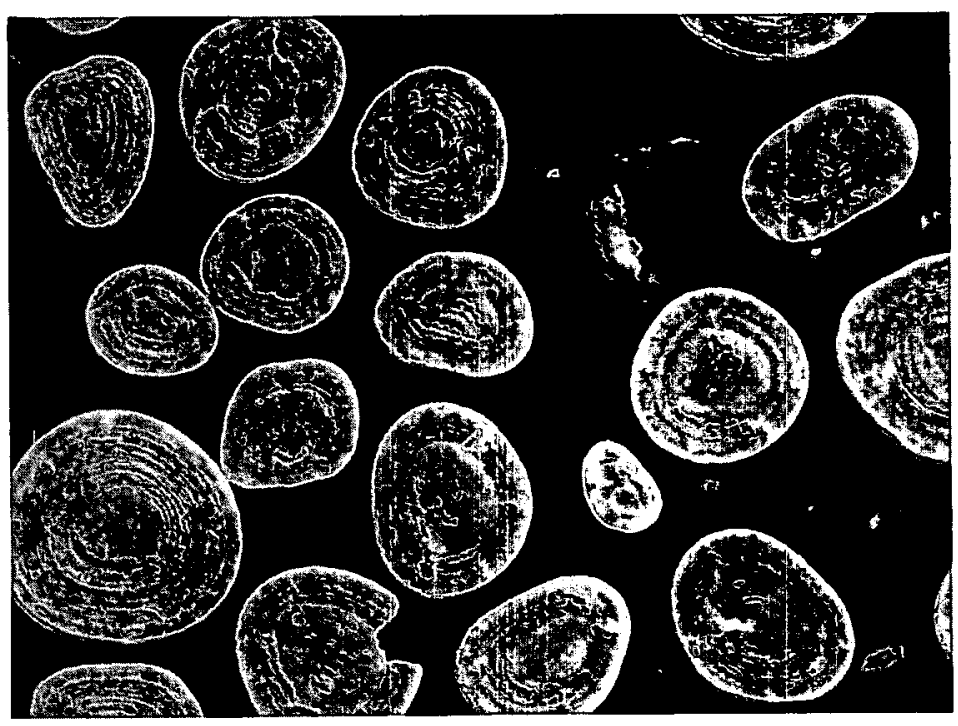

$108-5663$
Particle Density, $9.3 \mathrm{~g} / \mathrm{cc}$ Etched $60 \mathrm{sec}$ with One Part Conc, $\mathrm{H}_{2} \mathrm{SO}_{4}$, Nine Parts $30 \% \mathrm{H}_{2} \mathrm{O}_{2}$ (Magnification - 37X)

Figure 12

CROSS SECTION OF DENSE URANIUM DIOXIDE PARTICLE SHOWING FINE GRAIN STRUCTURE

Particle Density, $9.7 \mathrm{~g} / \mathrm{cc}$

(Magnification - 533X)

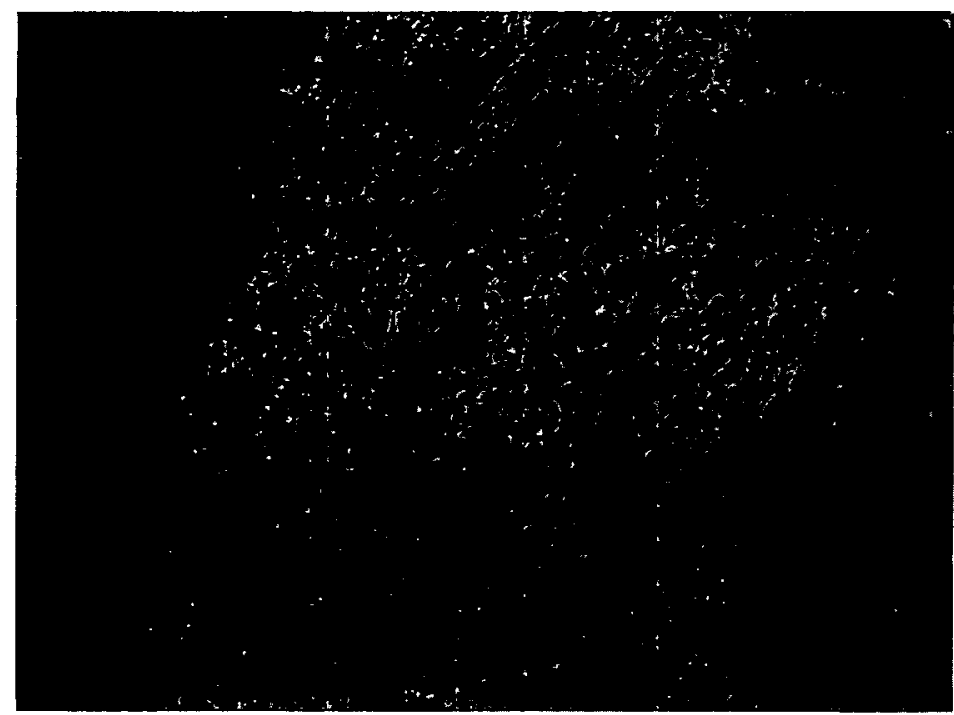


A high-temperature firing ( 1600 to $1725 \mathrm{C}$ for about $2 \frac{1}{2} \mathrm{hr}$ ) eliminated much of the fine pore structure (see Fig. 13) and produced a more dense material. Final particle densities ranged from about 10.4 to about $10.6 \mathrm{~g} / \mathrm{cc}$, or about 95 to 96.5 percent of theoretical density (see Table 16). The sintered particles retained their integrity and in appearance were much like the particles shown in Fig. 10. These data are very encouraging in that a relatively inexpensive procedure appears to be capable of producing material which is directly suitable for use as a reactor fuel in bulk form (for vibratory compacted or swaged fuel elements). Final evaluation of this material awaits results of compaction and irradiation studies.

Figure 13

\section{CROSS SECTION OF DENSE URANIUM DIOXIDE PAR TICLE SHOWING STRUCTURE AFTER SINTER- ING IN HYDROGEN AT $1700 \mathrm{C}$}

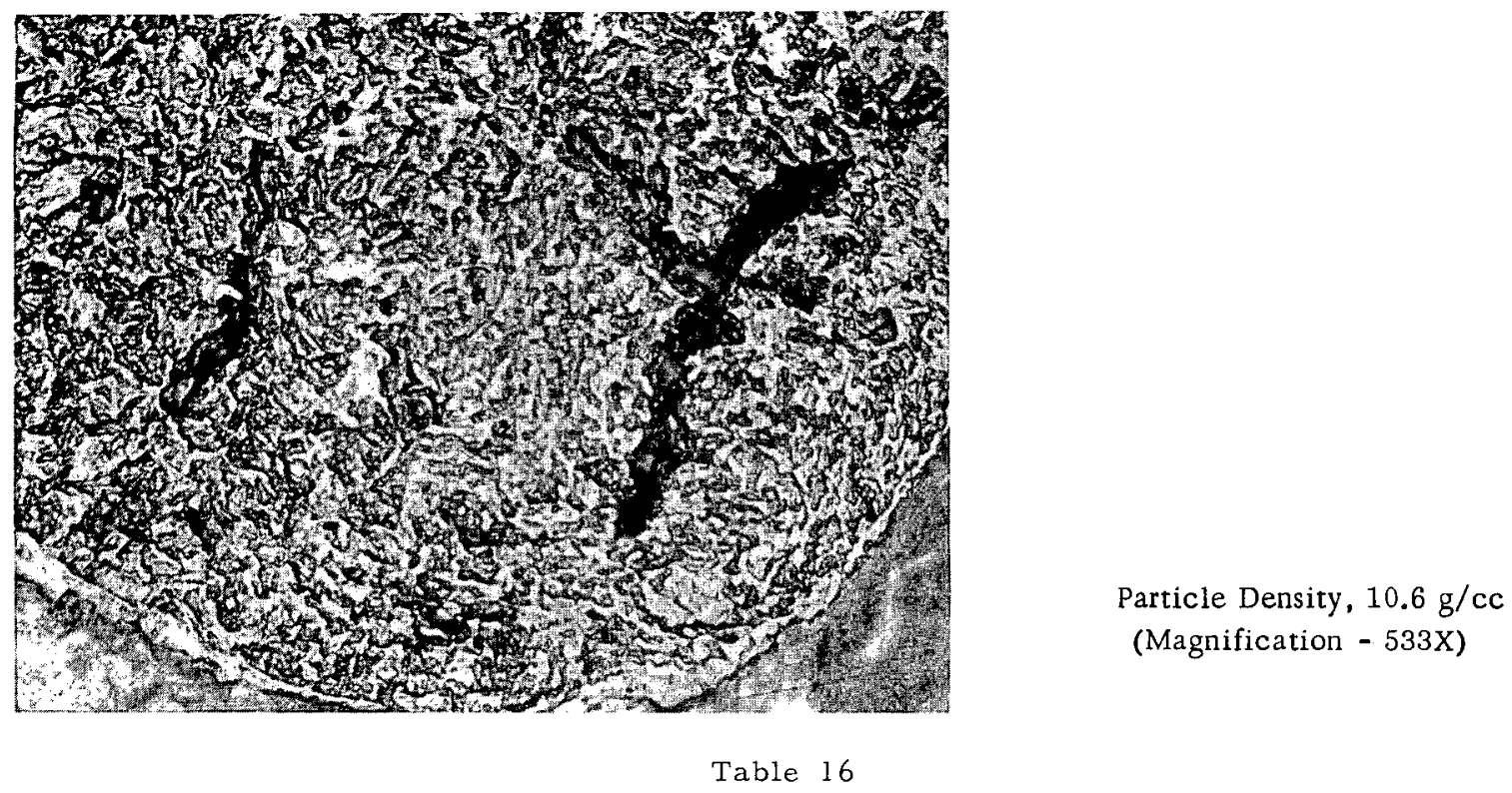

RESULTS OF SINTERING TESTS ON DENSE URANIUM DIOXIDE PAR TICLES PRODUCED IN THE FLUID BED BY THE SIMULTANEOUS REACTION PROCEDURE

Particle Size: Sintering Atmosphere: Sintering Schedule:
$-20+200$ mesh

Hydrogen (with about 300 ppm oxygen as impurity) $20 \mathrm{C}$ to $900 \mathrm{C}$ in about $2 \mathrm{hr}, 900 \mathrm{C}$ to $1700 \mathrm{C}$ in about $5 \mathrm{hr}$, in the range $1600 \mathrm{C}$ to $1725 \mathrm{C}$ for about $2 \frac{1}{2} \mathrm{hr}$.

Particle Density (g/cc)

$\begin{array}{ccc}\text { Run No. } & \text { Before Sintering } & \text { After Sintering } \\ 66-\mathrm{O} & 9.75 & 10.6 \\ 66-\mathrm{N} & 9.0 & 10.4 \\ 66-\mathrm{L} & 8.5 & 10.4\end{array}$


B. A Bench-scale Study of the Vapor-phase Reaction of Steam and Uranium Hexafluoride

Bench-scale experiments on the vapor-phase reaction of steam with uranium hexafluoride were conducted to determine what effect a low reaction temperature $(110 \mathrm{C})$ and the steam-to-hexafluoride ratio might have on the type of uranyl fluoride produced. It was thought that, if a stable hydrate of uranyl fluoride could be produced, the hydrate might be more reactive to hydrogen reduction and thereby might lead to the production of a more active uranium dioxide product (one with higher surface area) which would, in turn, sinter better.

The experimental apparatus consisted of a small cylinder containing uranium hexafluoride, a steam supply, a reactor made of $\frac{3}{4}$-in. - OD copper tubing packed with $\frac{1}{4}$-in. nickel Raschig rings, and the necessary flow metering, temperature measurement, and control equipment. The steam and the hexafluoride were introduced to the reactor, which was preheated to the desired temperature. The solid products of the reaction deposited on the packing. The entire reactor assembly was transferred to a dry-box where samples of the product could be prepared for analysis.

The results of $X$-ray diffraction analysis on the products from three typical runs are shown in Table 17. The letters $\underline{A}, \underline{f}$, and $\underline{k}$ were assigned by Brooks et al.,(26) to different forms of uranyl fluoride. Compound $A$ was designated as "anhydrous" uranyl fluoride despite the fact that the same diffraction pattern was obtained for $\mathrm{UO}_{2} \mathrm{~F}_{2} \cdot \mathrm{x} \mathrm{H}_{2} \mathrm{O}$ with $\mathrm{x}$ ranging from 0 to 1.0 .

Table 17

IDENTIFICATION OF TYPES OF URANYL FLUORIDE FORMED BY GAS-PHASE REACTION OF URANIUM HEXAF LUORIDE AND STEAM

Equipment:

$\frac{3}{4}$-in. -OD copper reactor

Types of Uranyl Fluoride: A - Anhydrous uranyl fluoride

$\underline{\underline{f}}$ - Stable hydrate

$\underline{\mathrm{k}}$ - Hydrate containing some hydrogen fluoride as identified by Brooks et a1. (26)

Reactor

Mole Ratio $\mathrm{H}_{2} \mathrm{O} / \mathrm{UF}_{6}$

$2: 1$

4.6

9.1
Temperature

(C)

109

111 to 121

105 to 115
Type of Uranyl Fluoride

\begin{tabular}{cc}
\hline Major Component & $\frac{\text { Minor Component }}{\underline{f}}$
\end{tabular}


Compound $\underline{f}$, which was found to be the most stable hydrate, was formed when $A$ was exposed to room humidity. The diffraction pattern for $\underline{f}$ is obtained for a series of hydrates in which the moles of water, $x$, ranges from 1.1 to 2.7. Compound $\underline{k}$ is a hydrate which may contain some hydrogen fluoride. Its pattern is observed after the "anhydrous" uranyl fluoride is exposed to air. After long exposure to air, $\underline{k}$ is converted to $\underline{f}$. Brooks et $\underline{a l}$., found that both the $\underline{f}$ and $\underline{k}$ hydrates were converted to the anhydrous $\underline{A}$ form when heated to $110 \mathrm{C}$. Since the "anhydrous" uranyl fluoride was found to be the major component in the run in which the high steam-to-hexafluoride mole ratio was used and since it was also present in the other runs, it is believed that the hydrates $\underline{f}$ and $\underline{\mathrm{k}}$ were not formed during the uranium hexafluoride hydrolysis experiment but were formed during a period of storage prior to the analysis of the samples. During this period, the samples were stored in containers which were closed but not desiccated. Since no further measurements, such as the determination of these materials of the surface. area of these materials, were made, no conclusions concerning their reactivity can be drawn.

C. Method Used for Calculating Particle Growth Rates

Assuming 100 percent deposition of product on the fluidized bed particles for reactions such as described in Section IV.A., the following methods were used for calculating particle growth rates. One method as sumes that the bed weight remained constant, and the other assumes that a constant number of particles were present in the bed.

1) Constant Bed Weight

The increase in particle diameter, $\mathrm{dD}$, is equal to twice the thickness of the deposited layer:

$$
d D=2 \frac{d V}{N \pi D^{2}}
$$

where

$$
\begin{aligned}
& D=\text { average particle diameter } \\
& V=\text { volume of deposited material } \\
& N=\text { number of particle. }
\end{aligned}
$$

The number $\mathrm{N}$ may be expressed in terms of the volume of the solids in the bed, $V_{B}$, and the particle diameter:

$$
N=\frac{V_{B}}{\frac{\pi}{6} D^{3}} .
$$


Substituting for $\mathrm{N}$ in Eq. (1) and rearranging,

$$
\frac{\mathrm{d} D}{\mathrm{D}}=\frac{\mathrm{l}}{3 \mathrm{~V}_{\mathrm{B}}} \mathrm{dV}
$$

which may be integrated and expressed as

$$
D=e^{\frac{V}{3 V_{B}}+C}
$$

where $C$ is a constant of integration. When $V=0, D=e^{C}=$ initial aver age particle diameter. Example:

Run 39, Table 1, page 12 where

$$
\begin{aligned}
& D_{\text {initial }}=207 \mu \\
& D_{\text {initial }}=\mathrm{e}^{\mathrm{C}}=207 \mu \\
& \mathrm{C}=\ln 207=5.333 .
\end{aligned}
$$

Assuming similar densities for the particles in the bed and the deposited layer, a weight ratio may then be substituted for the volume ratio in Eq. (4):

$$
D_{\text {final }}=e^{\frac{9630}{3 \times 8510}+5.333}=e^{5.710}=302 \mu \text {. }
$$

2) Constant Number of Particles

The increase in particle diameter may also be calculated for the case in which no change in the number of particles has occurred as in runs in which no product withdrawal was made (see Table 6, page 21). The basis for calculation then becomes the increase in the total volume of the bed:

$$
\begin{aligned}
& N=\frac{V_{i}}{\frac{\pi}{6} D_{i}^{3}} ; \\
& D_{f}=\sqrt[3]{\frac{V_{f}}{N \frac{\pi}{6}}},
\end{aligned}
$$

where 


$$
\begin{aligned}
& D=\text { average particle diameter } \\
& V=\text { volume of bed } \\
& N=\text { number of particles } \\
& \underline{i} \text { and } \underline{f} \text { are initial and final values. }
\end{aligned}
$$

For continuous runs where product is withdrawn from the bed batchwise, an incremental method of calculation using this procedure may be applied.

\section{ACKNOW LEDGEMENT}

The authors wish to acknowledge the direction and continued interest shown in this work by S. Lawroski, A. A. Jonke, and other members of the Chemical Engineering Division, the supporting vapor-phase studies by J. T. Holmes on the hydrolysis reaction (see Appendix, page 37), and the cooperation of the Analytical Group under Dr. R. P. Larsen. We are also indebted to $M$. Jones as the mainstay of the Operating Group. 